\title{
Human glial chimeric mice reveal astrocytic dependence of JC virus infection
}

\author{
Yoichi Kondo,, ${ }^{1,2}$ Martha S. Windrem, ${ }^{1,2}$ Lisa Zou, ${ }^{1}$ Devin Chandler-Militello, ${ }^{1}$ Steven J. Schanz, ${ }^{1}$ Romane M. Auvergne, ${ }^{1}$ \\ Sarah J. Betstadt, ${ }^{3}$ Amy R. Harrington, ${ }^{3}$ Mahlon Johnson, ${ }^{4}$ Alexander Kazarov, ${ }^{5}$ Leonid Gorelik, ${ }^{5}$ and Steven A. Goldman ${ }^{1,2,6}$ \\ 'Center for Translational Neuromedicine, ${ }^{2}$ Department of Neurology, ${ }^{3}$ Department of Obstetrics and Gynecology, and ${ }^{4}$ Department of Pathology, University of Rochester, Rochester, New York, USA. \\ ${ }^{5}$ Biogen Idec Inc., Cambridge, Massachusetts, USA. ${ }^{6}$ Faculty of Health and Medical Sciences, University of Copenhagen, Copenhagen, Denmark.
}

\begin{abstract}
Progressive multifocal leukoencephalopathy $(P M L)$ is a demyelinating disease triggered by infection with the human gliotropic JC virus (JCV). Due to the human-selective nature of the virus, there are no animal models available to investigate JCV pathogenesis. To address this issue, we developed mice with humanized white matter by engrafting human glial progenitor cells (GPCs) into neonatal immunodeficient and myelin-deficient mice. Intracerebral delivery of JCV resulted in infection and subsequent demyelination of these chimeric mice. Human GPCs and astrocytes were infected more readily than oligodendrocytes, and viral replication was noted primarily in human astrocytes and CPCs rather than oligodendrocytes, which instead expressed early viral T antigens and exhibited apoptotic death. Engraftment of human GPCs in normally myelinated and immunodeficient mice resulted in humanized white matter that was chimeric for human astrocytes and GPCs. JCV effectively propagated in these mice, which indicates that astroglial infection is sufficient for JCV spread. Sequencing revealed progressive mutation of the JCV capsid protein VP1 after infection, suggesting that PML may evolve with active infection. These results indicate that the principal CNS targets for JCV infection are astrocytes and GPCs and that infection is associated with progressive mutation, while demyelination is a secondary occurrence, following $T$ antigen-triggered oligodendroglial apoptosis. More broadly, this study provides a model by which to further assess the biology and treatment of human-specific gliotropic viruses.
\end{abstract}

\section{Introduction}

Progressive multifocal leukoencephalopathy (PML) is a demyelinating condition characterized by the degenerative loss of cerebral white matter after infection by JC virus (JCV; also known as JCPyV), a normally latent polyoma virus that becomes virulent in the setting of immunosuppression $(1,2)$. JCV is gliotropic and associated with oligodendrocytic loss in humans, but the humanselective nature of its infectivity and glial pathology has prevented the establishment of informative animal models of PML. As a result, prior studies have focused on modeling the systemic spread of JCV infection in mice with humanized immune systems (3) and in mice in which preinfected cells were delivered to the brain (4), but no experimental studies have yet achieved infection of the adult CNS by JCV or permitted modeling of the progressive demyelination of PML. On that basis, we asked whether mice neonatally engrafted with human glial progenitor cells (GPCs), whose forebrain glial populations become substantially humanized with age, might be able to support JCV infection and manifest the clinical hallmarks of PML, white matter gliosis and demyelination. We therefore engrafted newborn immunodeficient and myelin-defi-

\section{Related Commentary: p. 5103}

Authorship note: Yoichi Kondo and Martha S. Windrem contributed equally to this work. Conflict of interest: This work was supported in part by Biogen Idec, of which A. Kazarov and L. Gorelik are employees and for which S.A. Goldman has served as a paid consultant. Submitted: April 16, 2014; Accepted: September 4, 2014.

Reference information: J Clin Invest. 2014;124(12):5323-5336. doi:10.1172/JCI76629. cient homozygous shiverer ( $\left.\operatorname{Rag2^{-/-}} M b p^{s h i / s h i}\right)$ mice with bipotential GPCs isolated from fetal human brain tissue, thereby generating human glial-chimeric mouse brains $(5,6)$.

The donor human GPCs with which these mice were engrafted were bipotential oligodendrocyte-astrocyte progenitor cells, identified by their expression of CD140a (also known as PDGFR $\alpha$ ) as well as by gangliosides and chondroitin sulfate proteoglycans recognized by the A2B5 and NG2 antibodies, respectively. In the neonatal mouse brain environment, the human GPCs preferentially expand and broadly migrate, so that over a several-month period postnatally, most murine glia are replaced by human glia, including astrocytes and their progenitors, as well as oligodendrocytes when congenitally hypomyelinated recipients are used as hosts (7). These mice develop a largely humanized glial environment; in

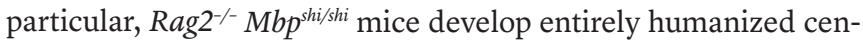
tral myelin. We postulated that the effective glial humanization of these mice might permit their productive in vivo infection by cell type- and species-specific human gliotropic viruses. To address

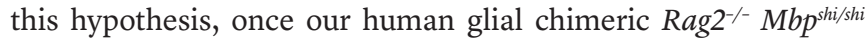
animals grew to maturity, we injected them intracerebrally with live JCV of several distinct virulent strains, including type $1 \mathrm{~A}$ (referred to herein as Mad-1 JCV) and the type 2A JCV archetype, and several patient-isolated mutant isoforms thereof (8). We then assessed the consequent JCV infection of GPCs, astrocytes, and oligodendrocytes using immunolabeling for both early viral $\mathrm{T}$ antigen (T-Ag) and VP1 capsid protein.

The JCV-injected human glial chimeric Rag2 ${ }^{-/-} M b p^{\text {shishi }}$ mice developed widespread infection of their integrated human glia, 
and this process was accompanied by local demyelination in association with regions of frank gliosis. The resultant humanized rodent model of JCV infection allowed us to then ask a number of hitherto unapproachable questions regarding the genesis of PML. What is the phenotypic selectivity of JCV infection in vivo? Are oligodendrocytes indeed the principal target phenotype of the virus? What is the principal reservoir of infection? What are the kinetics of temporal spread of the virus? Using what cellular hosts, and by what anatomic pathways, does it propagate and spread? Is the virus genetically stable during replication in the host? Does infectivity vary by viral genotype? Beyond addressing these questions in vivo, we also infected cultures of human fetal GPCs and their progeny with JCV in order to assess the cellular mechanisms of JCV toxicity as concurrent functions of time, cell cycle, and phenotype. We found that the principal targets of JCV were GPCs and astrocytes; that oligodendroglia were also infected, but later and less efficiently; that the virus actively mutated with viral spread; and, most remarkably, that infected oligodendroglia were not even necessary for viral propagation and spread. Our data thus indicate that JCV is principally a disease of astrocytes and their progenitors, with oligodendrocytic loss and demyelination a pathogenic but unnecessary concomitant to viral infection and spread.

\section{Results}

JCV efficiently infects astroglia and their progenitors in culture. Although PML has traditionally been viewed as a disease of oligodendrocytes, both astrocyte and GPC infection have been reported in vitro (9-13). Therefore, we first sought to assess the phenotypic selectivity of viral infection and propagation among the different phenotypes of human macroglia. We used either A2B5-directed immunoselection after PSA-NCAM depletion or CD140a-targeted selection to isolate human GPCs from secondtrimester fetal human brain. The resultant isolates were then aliquoted, with some cultures maintained as human GPCs in serumfree media supplemented with FGF2 and PDGF, while others were switched to tri-iodothyronine (T3) to bias oligodendroglial differentiation. In parallel, CD44-based immunomagnetic sorting was used to select phenotypically restricted astroglia from matched samples. After at least 1 week in vitro, cultures of each phenotype were separately exposed to either JCV or vehicle control. At 3, 5, or 10 days thereafter, the cultures were immunostained for either T-Ag or VP1 ( $n=4$ experiments per marker per time point). At least 2,000 cells in total were analyzed for each phenotype at each time point ( $>500$ cells in $n=4$ human samples per experimental group). In the JCV-exposed CD140a- and CD44-sorted cultures, both $\mathrm{CD} 140 \mathrm{a}^{+}$human GPCs and glial fibrillary acidic proteinexpressing $\left(\mathrm{GFAP}^{+}\right)$astrocytes, respectively, were infected quickly and efficiently. Within days, each manifested robust expression of both early viral T-Ag and VP1 (Figure 1, A and B), neither of which was detected in vehicle controls. In contrast to the rapid course of astroglial infection, oligodendrocytic infection in vitro was delayed and initially of relatively low efficiency (Figure 1C; see Supplemental Figure 1 for individual immunolabels; supplemental material available online with this article; doi:10.1172/JCI76629DS1). At both 3 and 5 days postinfection (DPI), the incidence of T-Ag infection was significantly higher in cultured astrocytes than in oligodendrocytes $(P<0.01,2$-way ANOVA with Bonferroni post-hoc comparisons). VP1-defined viral replication was also significantly less common in oligodendroglia than in astrocytes at 3 and 5 DPI ( $P<0.01,2$-way ANOVA with Bonferroni post-hoc comparisons); indeed, $\mathrm{VP}^{+}$oligodendroglia were rarely noted in the first week after infection. Nonetheless, by 10 DPI, significant numbers of $\mathrm{VP}^{+}$oligodendroglia appeared as well, following the delayed rise in T-Ag-associated oligodendroglial infection (Figure 1, C-E). In astrocytes and oligodendrocytes alike, VP1-defined viral replication was associated with significant increments in nuclear size and DNA content (Supplemental Figure 2).

JCV initially infects astroglia in vivo. Since astrocytic infection was surprisingly more robust than that of oligodendrocytes in vitro, we next sought to define the relative phenotype-selective tropism and infectivity of JCV in vivo. Since JCV infects only human glia, we established human glial chimeric mice so as to provide an in vivo model for JCV infection and JCV-dependent demyelination. We injected neonatal $\mathrm{Rag}^{-/-} \mathrm{Mbp} \mathrm{p}^{\text {shishi }}$ mice with $2 \times 10^{5}$ human GPCs, delivered as $10^{5}$ cells/hemisphere in 2 intracallosal injections per side of $5 \times 10^{4}$ cells each. Myelination by neonatally engrafted human GPCs has been well characterized

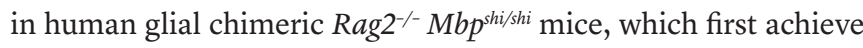
dense callosal and capsular myelination only after 3 months of age $(6,14)$. As a result, we assessed the effects of JCV in $\mathrm{Rag}^{-/-} \mathrm{Mbp} \mathrm{p}^{\mathrm{sh} / \mathrm{shi}}$ mice first injected with virus at 2,3 , or 4 months of age $(n=5,10$, and 3, respectively). At those time points, we delivered Mad-1 (type 1A) JCV to the human glial chimeras by stereotaxic intracallosal injection. The animals $(n=18$ total) were all killed at $20 \pm 1$ weeks of age, i.e., at 3-4, 6-8, or 11-12 weeks after infection $(n=3$, 10 , and 5 , respectively). Their brains were then assessed for both early and late JCV antigens, as well as for cellular pathology and myelin integrity (see Supplemental Table 1 for details of all mice assessed histologically).

We found that JCV induced the expression of the major early and late viral gene products (T-Ag and the VP1 capsid protein, respectively) in oligodendrocytes, astrocytes, and GPCs throughout the chimeric Rag2 ${ }^{-/-} M b p^{\text {shishi }}$ corpus callosum (Figure 2A). Infected astrocytes and GPCs were often magnocellular, with overtly enlarged nuclei, while processes of infected astrocytes manifested a bizarre fibrotic morphology (Figure 2B), as described previously in human PML (15). In contrast, at these early time points, relatively few infected myelin basic proteinexpressing $\left(\mathrm{MBP}^{+}\right)$oligodendroglia were noted, most of which expressed T-Ag rather than VP1 (Figure 2C and see below), suggestive of both relatively later infection and less viral replication compared with astrocytes. Importantly, infection was restricted to human cells; no murine cells expressed either early or late viral genes, and nonchimeric, unengrafted mouse controls manifested no evidence of infection after JCV injection (Figure 2D).

JCV infection in vivo results in demyelination of human chimeric white matter. To better understand the means by which demyelination occurs in JCV infection, we next examined the myelination of

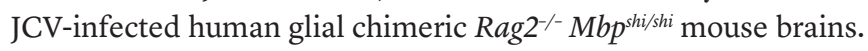
By 4 weeks after JCV infection, focal regions of demyelination and infection-associated astrogliosis were noted in the forebrain white matter of infected mice, typically in discrete foci abutting the callosal and fimbrial walls of the lateral ventricle (Figure 3, A and B). Importantly, while areas of demyelination were associated 

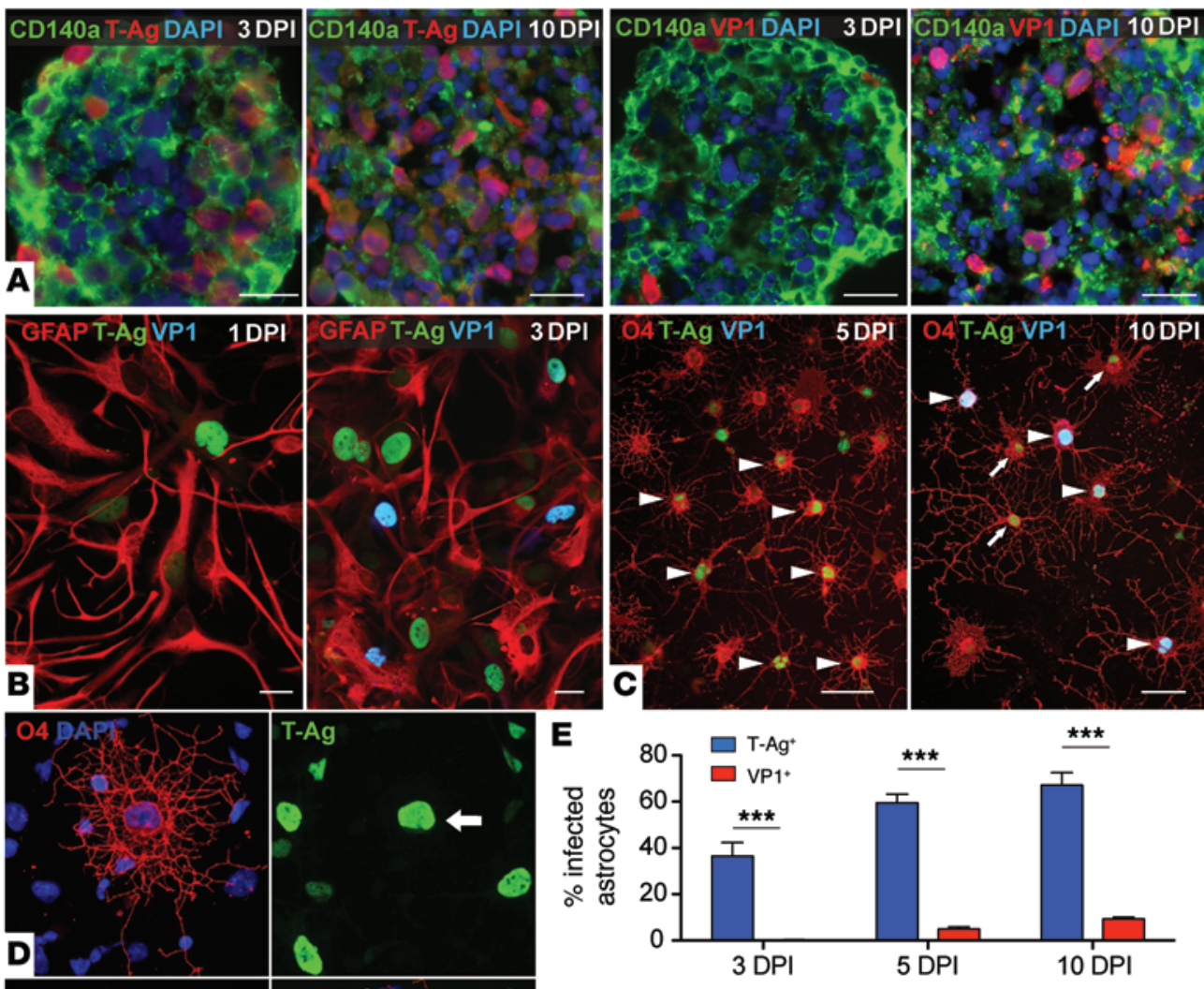

$\star \star \star$

VP1
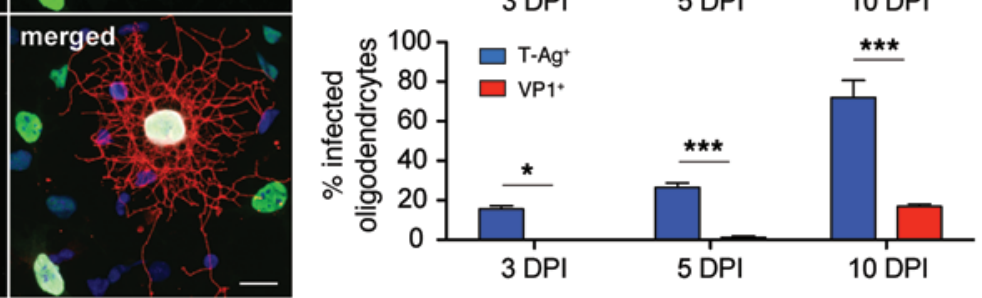

Figure 1. Human astroglia are most efficiently infected by JCV in vitro. Human GPCs and astrocytes were readily infected by JCV in vitro, with robust expression within days of both the early viral large T-Ag and the later VP1 capsid protein. (A) Both T-Ag and VP1 were expressed by CD140a+ GPCs grown in suspension culture, and both were more abundantly expressed at $10 \mathrm{DPI}$ than at $3 \mathrm{DPI}$. (B) In CD44-sorted GFAP' astrocytes, T-Ag was expressed as early as $1 \mathrm{DPI}$, whereas VP1 was first expressed at $3 \mathrm{DPI}$. (C) In contrast, 04+ oligodendrocyte infection in vitro was both delayed and of relatively low efficiency, showing weak T-Ag expression without VP1 at 5 DPI (arrowheads), with VP1 ${ }^{+}$ oligodendroglia (arrows) appearing only at $10 \mathrm{DPI}$. (D) Representative images of a JCV-infected T-Ag ${ }^{+} \mathrm{VP1} 1^{+}$oligodendrocyte at $10 \mathrm{DPI}$; nuclear hypertrophy (arrows) was apparent. (E) At 3 and 5 DPI, T-Ag+ oligodendroglial infection was of significantly lower efficiency than that of astrocytes, while oligodendrocytic VP1+ JCV replication was even less frequent. By $10 \mathrm{DPI}, \mathrm{VP}^{+}$oligodendroglia as well as astrocytes began to accumulate. Data are presented as percentage of cells of each phenotype at 3,5 , and $10 \mathrm{DPI}$. Scale bars: $20 \mu \mathrm{m}$. ${ }^{*} P<0.05 ;{ }^{* *} P<0.01$. tors, as cellular expression of the VP1 capsid protein, which is expressed by mature postreplication virions, was largely limited to astroglia and GPCs. Thus, astrocytes and GPCs may be the principal reservoirs for intracerebral viral propagation. In contrast, $\mathrm{VP}^{+}$human oligodendrocytes were uncommon, and inevitably appeared dying or pyknotic (Figure 2A); most infected oligodendroglia that could be identified as such in vivo were $\mathrm{T}-\mathrm{Ag}^{+}$, but $\mathrm{VP1}{ }^{-}$. This finding indicated that oligodendroglia are initially infected, but die or are lost before the VP1-identifiable completion of viral replication.

JCV infection in vivo spreads in different cell types at different rates. As a result of the humanselective nature of JCV infection, and the lack of early or phenotype-specific radiographic surrogates, the dynamics of viral propagation in the infected CNS remain unknown. We thus investigated the pattern of JCV spread in human glial chimeras, as a function of time after infection. We tracked the expansion and spread of both infected glia and of the fraction harboring replicating virus by immunostaining for $\mathrm{T}-\mathrm{Ag}$ and $\mathrm{VP} 1$, respectively. Both $\mathrm{T}-\mathrm{Ag}^{+}$ and $\mathrm{VP}^{+}$human cells were progressively more numerous and widespread as a function of time after infection, with infection progressing from the site of viral injection at 4 weeks to include much of the central white mat- with dense aggregations of $\mathrm{VP}^{+}$astrocytes, $\mathrm{VP} 1^{+}$oligodendroglia were rare, despite overt oligodendrocytic loss and demyelination (Figure 3, A-D). By 12 weeks postinfection, demyelination was widespread and associated with regions of focal gliosis embedded within demyelinated loci. At these longer postinfection time points, diffuse hypomyelination of the callosa and capsules of

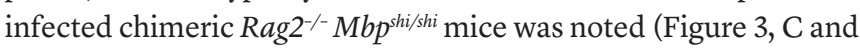
D); oligodendrocytic VP1 expression remained unusual, but T-Ag immunolabeling revealed large numbers of infected oligodendrocytes (Figure 3D). Human chimeric controls by that time point exhibited dense human GPC-derived myelination (Figure 3E).

These observations suggest that the principal direct targets of JCV infection in the adult CNS are astrocytes and their progeni- ter at 12 weeks (Figure 4A). Notably, despite ample evidence of astrocytic viral replication, as defined by VP1 expression, by astrocytes and GPCs alike (Figure 4, B, D, and E), a high proportion of $\mathrm{T}-\mathrm{Ag}^{+}$glia remained viable but $\mathrm{VP1}{ }^{-}$; indeed, the ratio of $\mathrm{T}^{-\mathrm{Ag}^{+}}$glia to $\mathrm{VP}^{+}$glia increased with time over the 12-week observation period (Figure $4 \mathrm{~B}$ ), suggestive of an accelerated rate of infection. While these $\mathrm{T}^{-} \mathrm{Ag}^{+} \mathrm{VP1}^{-}$infectants included oligodendrocytes, most were astroglial; both the density and relative proportions of $\mathrm{T}-\mathrm{Ag}^{+} \mathrm{MBP}^{+}$oligodendrocytes were significantly lower than those of $\mathrm{T}-\mathrm{Ag}^{+}$astrocytes and GPCs at all time points $(P<0.05$, ANOVA with post-hoc comparisons as well as linear regression of $\mathrm{T}^{-} \mathrm{Ag}^{+}$cell density on length of infection; Figure 4C). Interestingly, while the $\mathrm{T}-\mathrm{Ag}^{+}$infection rate of both GPCs 
A
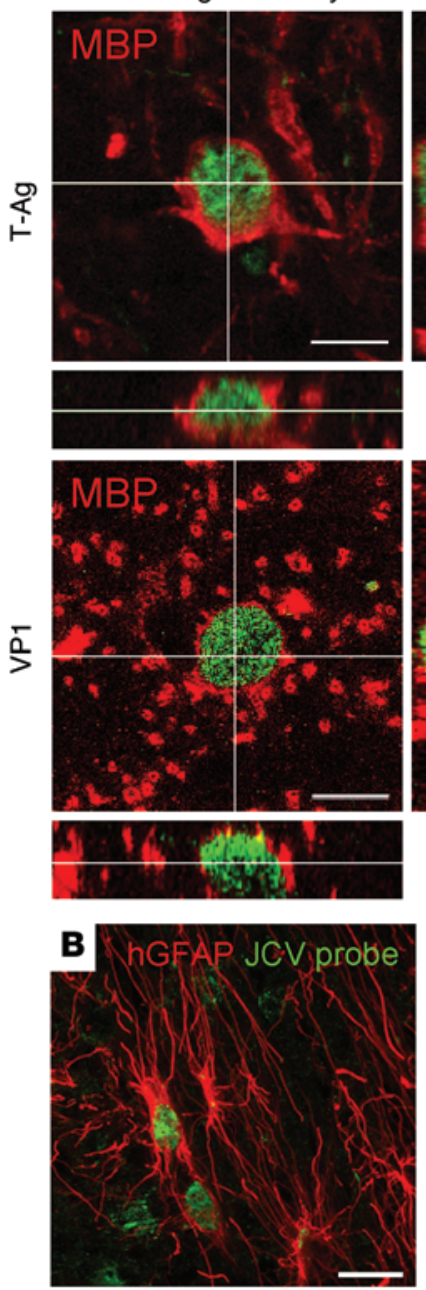
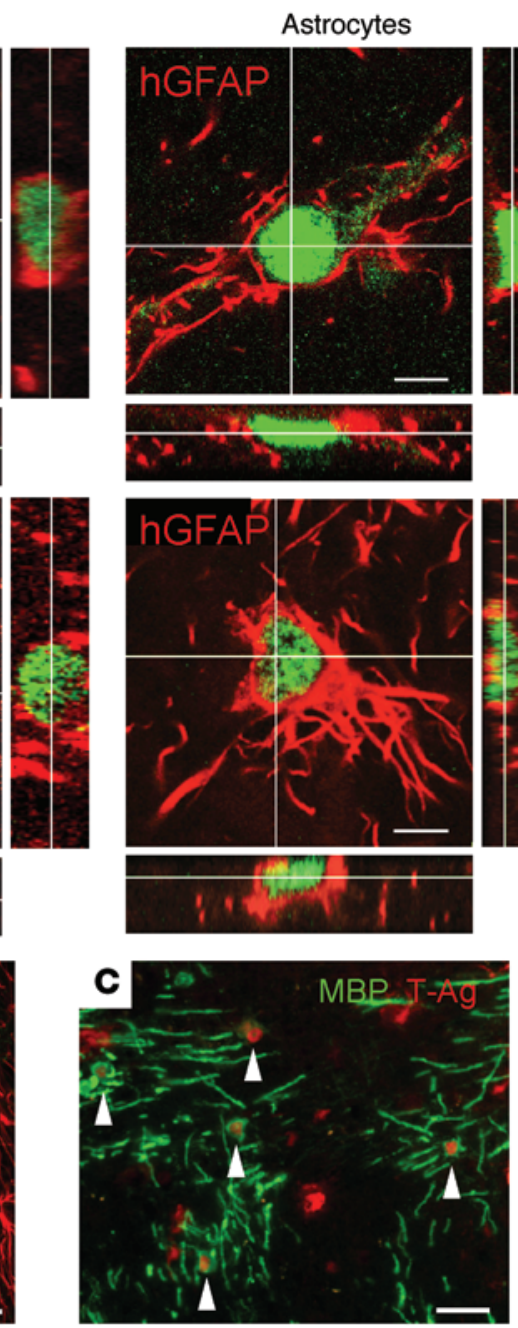

GPCs
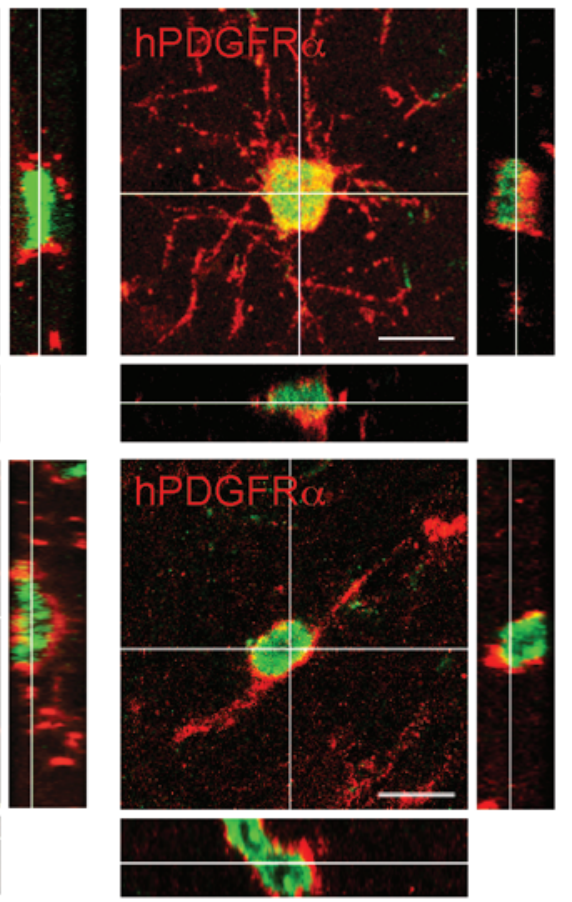

D

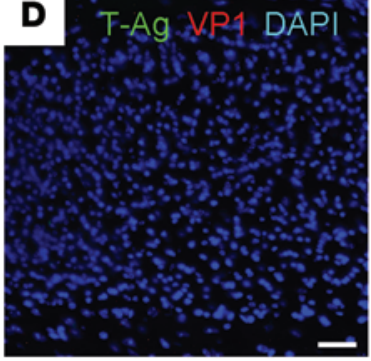

Figure 2. JCV replicates more rapidly and efficiently in astroglia than in oligodendrocytes in vivo. JCV induced the expression of the major early and

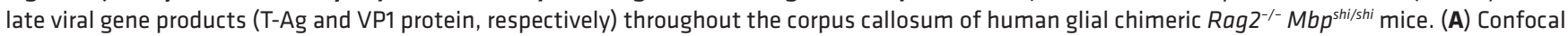

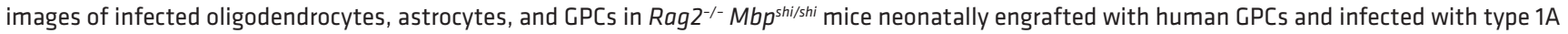
(Mad-1) JCV for 12 weeks. (B) By 12 weeks, infected astrocytes were highly abundant and largely magnocellular, with overtly enlarged nuclei and bizarrely fibrotic processes. (C) In contrast, substantial human oligodendrocytic loss was evident by 12 weeks after infection, and most of the infected remainder expressed T-Ag (arrowheads), as exemplified by the $\mathrm{T}-\mathrm{Ag}^{+} \mathrm{MBP}^{+}$oligodendroglia shown; only human oligodendroglia expressed $\mathrm{MBP}^{\text {in }}$ Rag $2^{-1-} \mathrm{Mbp}^{\text {shi/shi }}$ brain. (D) Infection was restricted to human cells; in this example, unengrafted mouse corpus callosum manifested no evidence of infection 12 weeks after JCV injection. Scale bars: $20 \mu \mathrm{m}$ (A); $50 \mu \mathrm{m}$ (B and C); $100 \mu \mathrm{m}$ (D).

and astrocytes was significantly higher than that of oligodendrocytes, consistent with the substantially greater infectivities of both GPCs and astrocytes noted in vitro, $\mathrm{VP} 1^{+}$astrocyte and GPC density in vivo remained relatively low and did not differ from that of oligodendrocytes (Figure 4, D-F). This appeared to reflect the rapid clearance of infected cells once they reached the stage of viral replication; $\mathrm{VP1}{ }^{+}$astroglia and GPCs were lost due to viral-induced hypertrophy and lysis and appeared never to accumulate as such, despite their higher incidence and density of infection. Together, these data indicated that JCV infection and replication were significantly less robust in oligodendroglia than in GPCs and astrocytes, and that the latter proved more efficient as vehicles for viral spread. As postmitotic cells, oligodendrocytes might then be merely the victims of JCV infection, and not significant contributors to viral propagation and spread.
JCV does not require oligodendrocytes for viral infection and spread. Since astroglia appeared sufficient for both viral infection and propagation, we next asked whether oligodendrocytes were even necessary for viral spread in vivo. To this end, we injected Mad-1 JCV into the callosa of 16-week-old immunodeficient but myelin WT human glial chimeric $\operatorname{Rag1}^{-/-}$mice $(n=5)$; these normally myelinated mice recruit few, if any, oligodendrocytes from the engrafted progenitor pool, so that their human cell complement remains limited to GPCs and astrocytes (7). At 12 weeks after viral injection (i.e., 28 weeks of age), the expansion of $\mathrm{VP} 1^{+}$infected cells within these chimeric Rag1 $1^{-/-}$hosts was grossly similar to

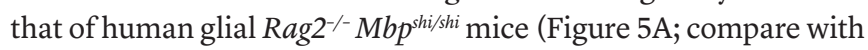
Figure 4A). Importantly, however, the compartmental pattern of viral spread differed in the recipient phenotypes. In Rag1 $^{-/}$chimeras, in which human donor cells integrated only as astrocytes and 

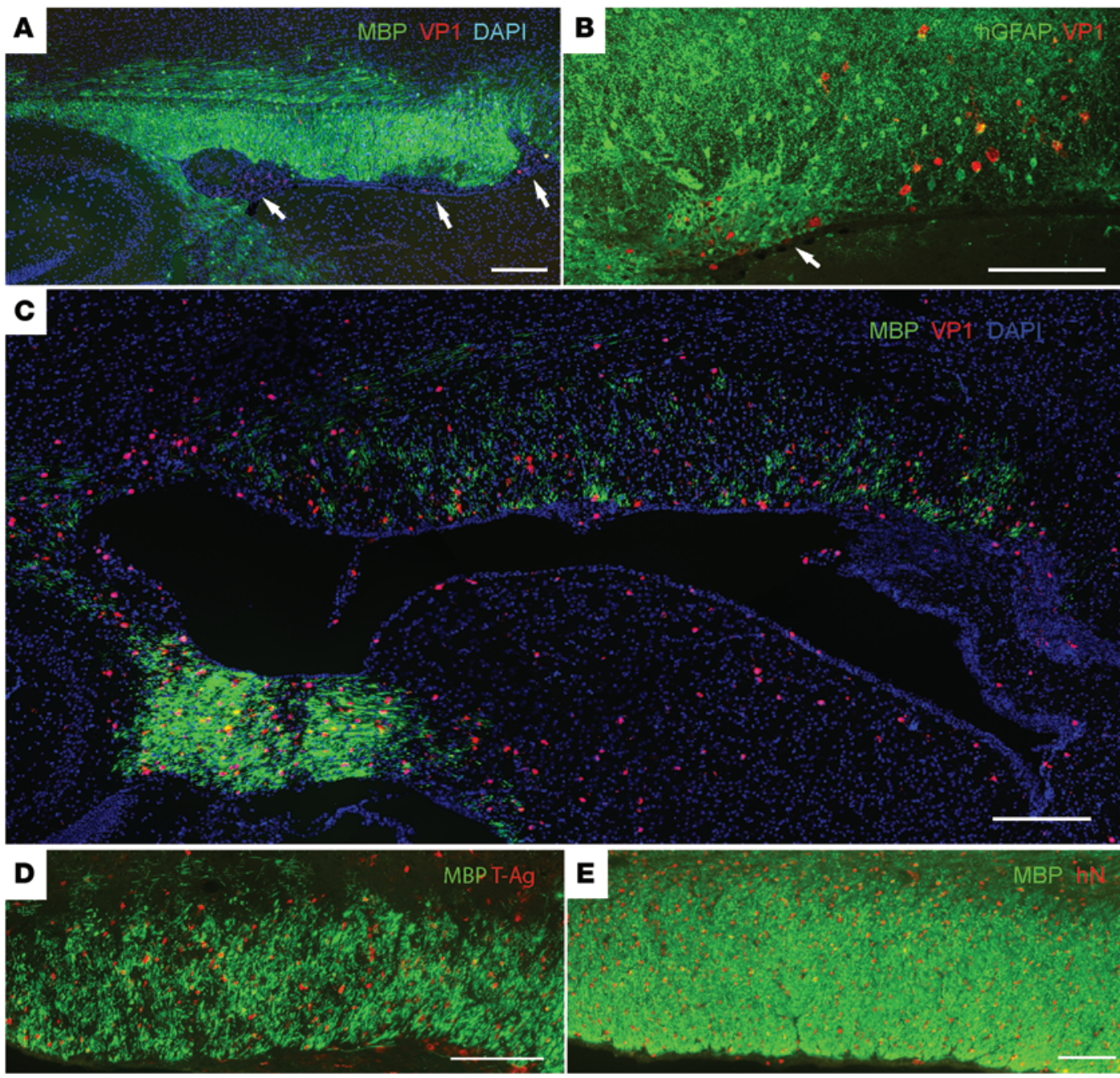

Figure 3. JCV infection of human glial chimeras triggers both focal and diffuse demyelination. (A and B) At 4 weeks after viral infection, focal regions of demyelination (A, arrows) and infection-associated astrogliosis (B, arrow) were noted in the forebrain white matter of infected mice, typically in discrete foci abutting the callosal wall of the lateral ventricle. hGFAP, human GFAP. (C and D) By 11 weeks after infection, diffuse hypomyelination of the callosa and capsules of infected chimeric mice was noted. (E) Uninfected human chimeric controls by 20 weeks after transplantation exhibited dense GPC-derived myelination, as did JCV-injected non-xenografted murine controls (not shown). hN, human nuclear antigen. Scale bars: $200 \mu \mathrm{m}$ (A and C); $100 \mu \mathrm{m}$ (B, D, and E).

GPCs, but not oligodendrocytes, JCV infection predominated in the cortex (Figure 5, B-E). This sharply contrasted the pattern of viral spread in the chimeric Rag2-- Mbp $p^{\text {shishi }}$ mice, in which human cells also engrafted as oligodendrocytes and fibrous astrocytes, and in which JCV infection was noted to preferentially spread in the white matter (Figure 5F). These observations indicated that oligodendroglia are not necessary for JCV propagation in vivo and that astroglia are sufficient to support viral infection and spread. Thus, these data strongly support the notion that astrocytes and GPCs serve as the principal reservoirs for JCV in vivo.

JCV-infected oligodendrocytes enter the cell cycle. Polyoma large T-Ag can trigger cell cycle entry and S-phase initiation by various mitotically quiescent somatic cell types, via binding to retinoblastoma protein $(\mathrm{Rb})$; the resultant progression to S-phase both permits and accelerates viral replication (16). On that basis, we next asked whether cell cycle initiation occurs in JCV-infected oligodendrocytes in PML, and if so, whether the induction of cell cycle in postmitotic human oligoden- droglia is sufficient to trigger their death. We immunolabeled infected oligodendrocytes in the engrafted Rag2-- $M b p^{\text {shisshi }}$ mouse for the mitosis-associated antigen Ki67 and found that $31.0 \% \pm 8.4 \%$ of infected mature $\mathrm{MBP}^{+}$oligodendrocytes were indeed $\mathrm{Ki}^{+} 7^{+}$, whereas no $\mathrm{Ki} 67^{+} \mathrm{MBP}^{+}$oligodendrocytes were found in matched uninfected controls (Figure 6, A and B).

To further investigate the relationship of JCV infection to aberrant oligodendrocytic cell cycle entry, we then infected cultured oligodendrocytes derived from CD14Oa $\mathrm{a}^{+}$human fetal GPCs. The plated GPCs were differentiated in vitro into $\mathrm{O}^{+}$oligodendroglia over 7 days, then infected with Mad-1 JCV at $10^{5}$ genome equivalents per cell (GE/cell). For each experiment, 4 matched runs were performed, each in triplicate for a total of 12 scored wells, which represented a minimum of 2,000 cells per group. When assessed at $5 \mathrm{DPI}, 26.5 \% \pm 2.2 \%$ of $\mathrm{O}^{+}$oligodendrocytes expressed $\mathrm{T}-\mathrm{Ag}$ (Figure $6 \mathrm{C}$ ), whereas only $1.3 \% \pm 0.6 \%$ expressed VP1. When reassessed at $10 \mathrm{DPI}, 58.4 \% \pm 2.0 \%$ of the T-Ag ${ }^{+} \mathrm{JCV}$-infected $\mathrm{O}^{+}$ oligodendrocytes coexpressed Ki67, indicative of their aberrant 
A
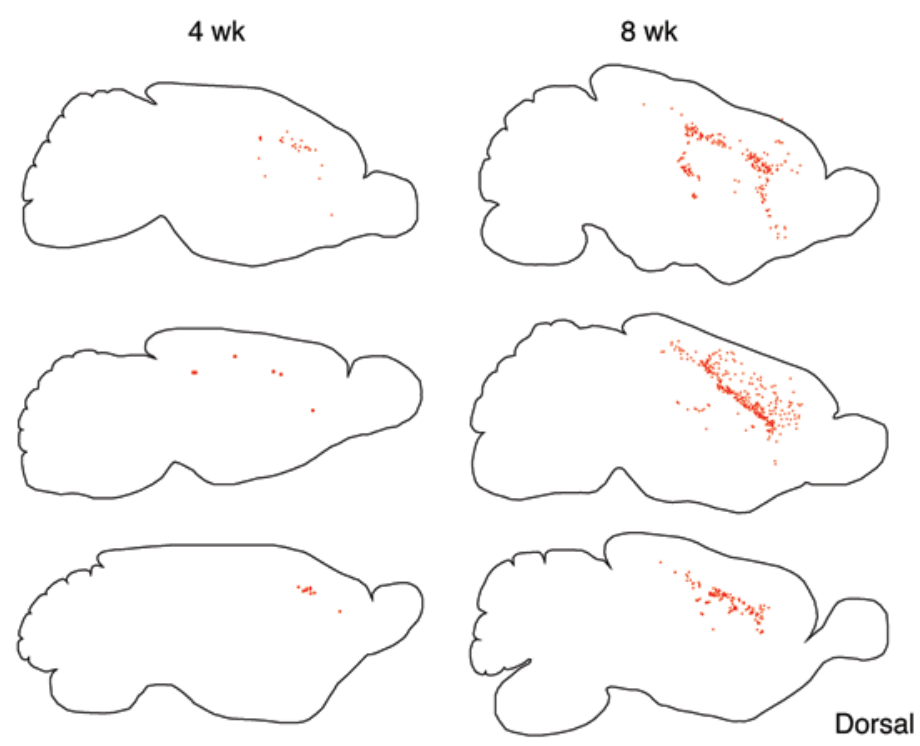

Dorsal

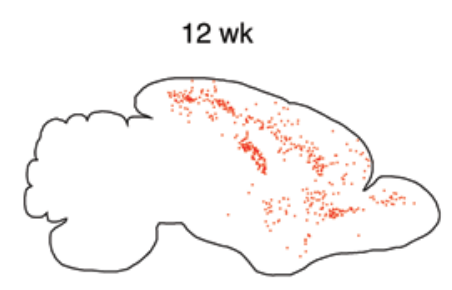

VP1+ human cell *
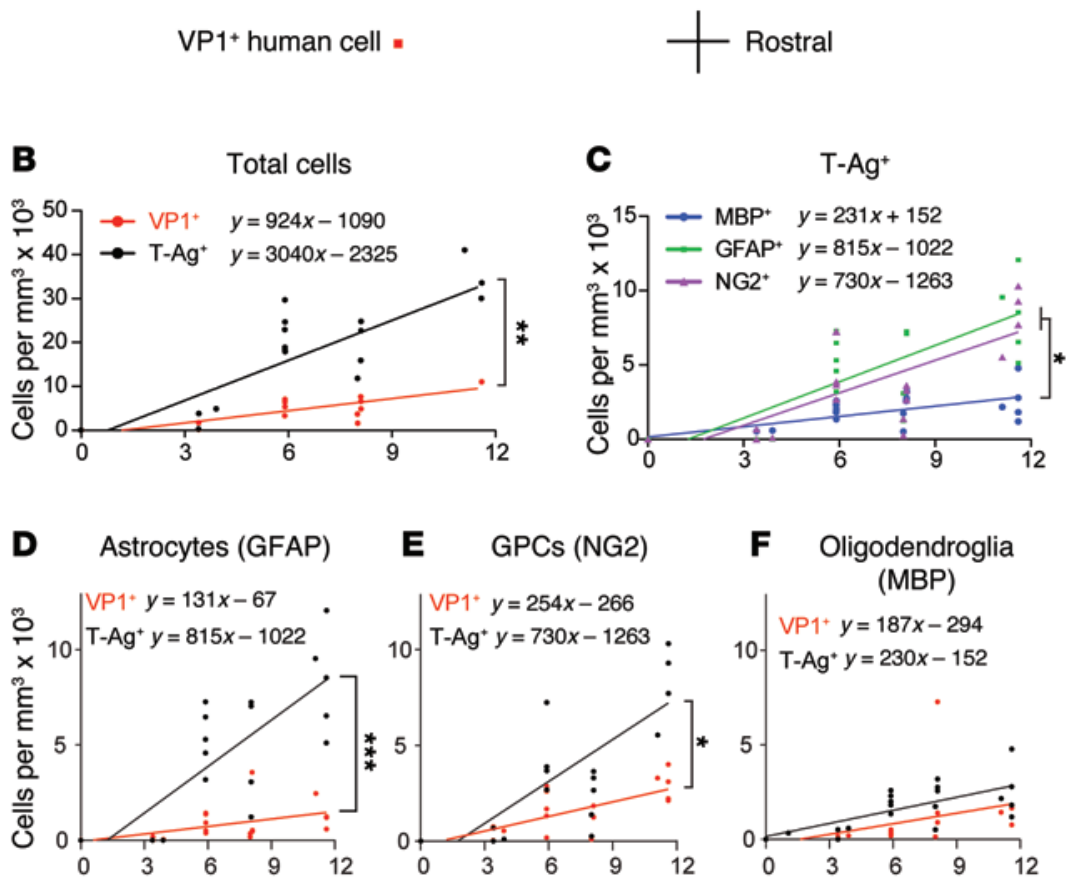

Length of infection (wk)

Figure 4. Viral propagation exhibits cell type-selective spread. JCV spread in vivo was tracked by immunostaining

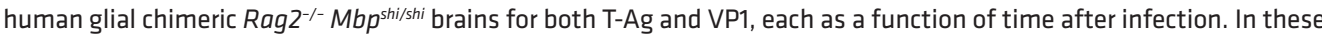

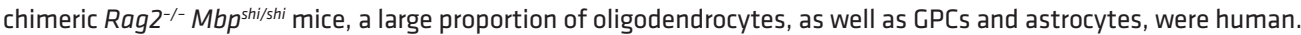

(A) Sagittal sections of 3 different infected chimeras at each of 3 time points; individual VP1+ cells are dot-mapped. VP1+ human cells became progressively more widespread with time, with JCV infection progressing from the site of viral injection to include much of the forebrain white matter by 12 weeks postinfection, with marked cortical spread by that point as well. (B) T-Ag ${ }^{+}$and $\mathrm{VP1}^{+}$cells, representing all JCV-infected cells and those in which viral replication has occurred, respectively, both accumulated as a function of time. (C) The number of $\mathrm{T}^{-\mathrm{Ag}^{+}}$astrocytes $\left(\mathrm{GFAP}^{+}\right)$and GPCs (NG2+) was significantly higher than that of $\mathrm{T}^{-} \mathrm{Ag}^{+}$oligodendroglia $\left(\mathrm{MBP}^{+}\right)$at all time points examined $(P<0.01$, repeated-measures 1-way ANOVA). Furthermore, the in vivo rates of accumulation of $\mathrm{T}^{-\mathrm{Ag}^{+}}$astrocytes and GPCs (reflecting the rate of infection among each cell type, estimated by regression line slope) were each significantly higher than that of oligodendrocytes ( $P<0.01$, linear regression). ( $\mathbf{D}-\mathbf{F})$ Despite their marked differences in T-Ag-defined infectivity and spread, astrocytes and oligodendrocytes did not differ in their rates of accumulation of $\mathrm{VP}^{+}$infectants, likely reflecting the rapid lytic loss of cells at that stage. ${ }^{*} P<0.05 ;{ }^{* *} P<0.01 ;{ }^{* *} P<0.001$. entry into cell cycle; conversely, uninfected $\mathrm{T}-\mathrm{Ag}$ oligodendrocytes in the same cultures exhibited no appreciable Ki67 expression (Figure 6D). These findings support the in vivo observation of $\mathrm{Ki}^{+} 7^{+} \mathrm{MBP}^{+}$ oligodendroglia in JCVinjected human glial chimeric Rag2- Mbp ${ }^{\text {shishi }}$ mice (Figure 6, A and B) and suggest that otherwise-postmitotic human oligodendroglia may be aberrantly induced into cell cycle entry by JCV infection.

JCV-induced cell cycle entry is associated with oligodendrocytic death. We next asked whether the T-Agassociated induction of oligodendrocytic cell cycle entry is sufficient to trigger oligodendrocytic death, since ectopic cell cycle entry has been associated with cell death in a variety of otherwise-postmitotic phenotypes. In particular, an analogous process of cell cycle activation-induced death has been described extensively in neurons, in which it has been explored as a mechanism of neurodegenerative cell loss (17-19), and apoptotic oligodendrocytic death has been observed in response to JCV $(20,21)$.

In vitro, we found that the number of viable $\mathrm{O}^{+}$ oligodendrocytes was significantly decreased at 10 DPI with type $2 \mathrm{~A} \mathrm{JCV}$ compared with otherwise-matched uninfected controls (Figure 6E); the diminished oligodendrocytic numbers of infected cultures were accompanied by a significant increase in the number of infection-associated dying oligodendrocytes, as defined by TUNEL (Figure 
A
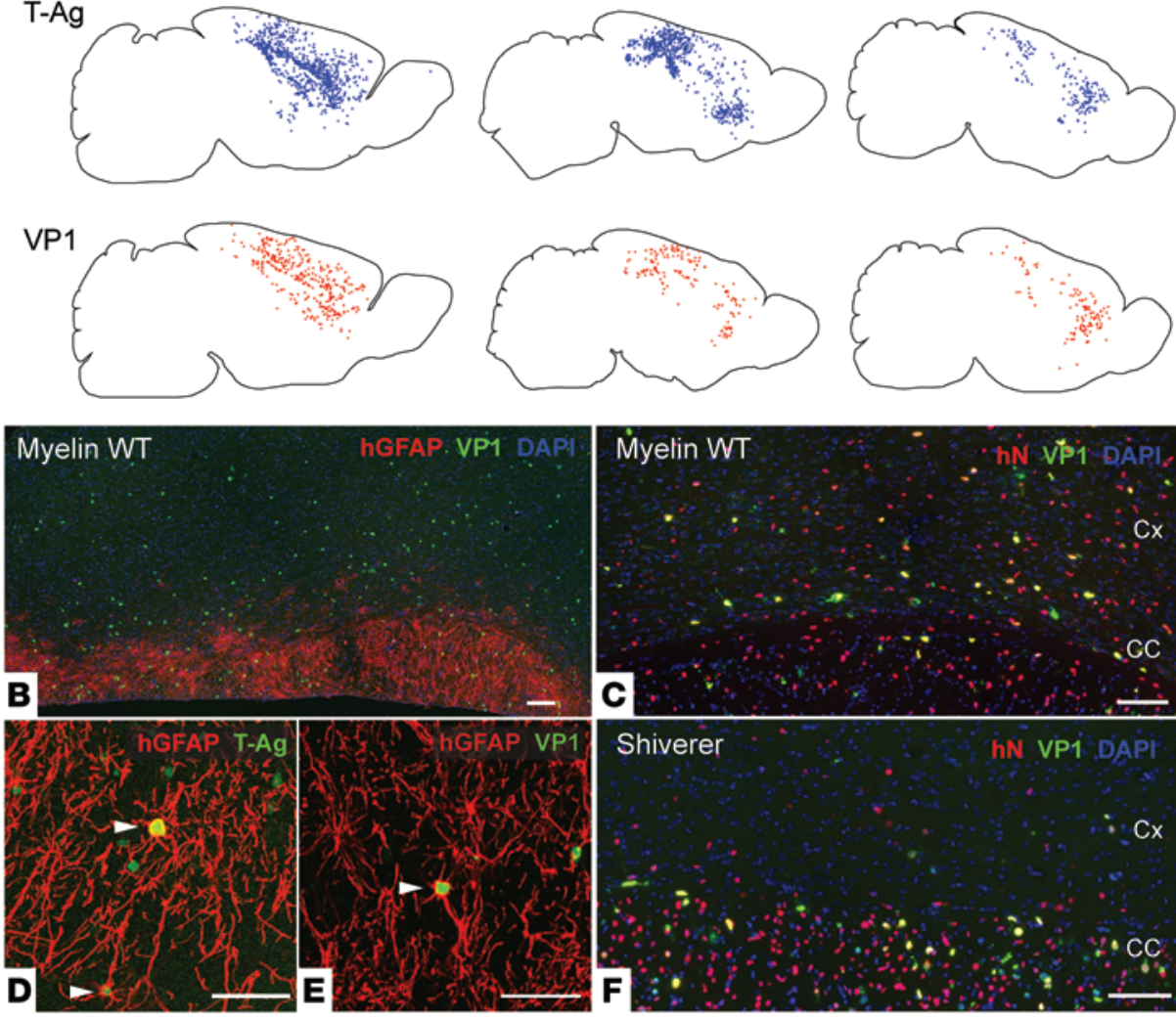

Figure 5. Astrocytes and GPCs are sufficient to support viral replication and spread in vivo. (A) JCV introduced into myelin WT Rag1/-- mice (colonized with human GPCs and astrocytes, but not oligodendrocytes) yielded viral propagation and geographic spread as rapid and extensive as that in human glial chimeric Rag2-/- Mbp shi/shi mice (in which human oligodendroglia were densely represented). Shown are distributions of $\mathrm{T}^{-\mathrm{Ag}^{+}}$and $\mathrm{VP}^{+}$cells mapped in $14-\mu \mathrm{m}$ sagittal sections of 3 different Rag $^{1 /-}$ mice injected with JCV as adults, 12 weeks previously. Infected human cells were widely distributed, despite the absence of human oligodendroglia. (B) Sagittal section along the callosal length of a chimeric myelin WT Rag1 $1^{-/-}$mouse 12 weeks after infection, showing widespread infection and VP1 expression by GFAP' subcortical human astrocytes and GFAP- cortical human astrocytes and GPCs. (D and E) Higher-magnification views showing the predominance of infected cells (arrowheads) in Rag1/- cortical grey, including both $\mathrm{T}_{-} \mathrm{Ag}^{+}$(D) and $\mathrm{VP}^{+}$(E) glia, manifesting the typical hypertrophic nuclei of cells that have undergone viral replication. (F) Conversely, VP1+ glia in the corpus callosum of a human glial chimeric Rag2/- Mbp shi/shi mouse 12 weeks after type 1A (Mad-1) JCV infection showed the predominant white matter spread of virus in these mice, which manifested both oligodendrocytic and astrocytic infection (compare with the Rag1/-- section in C). Notably, since JCV can only infect human cells, the potential volume of infection in these mice was limited by the geographic dispersal of the resident human oligodendrocyte progenitor cells. Since these mice were given only forebrain injections so as to produce forebrain-only human glial chimeras, all JCV infection in these mice was limited to the forebrain. CX, cerebral cortex; CC, corpus callosum. Scale bars: $100 \mu \mathrm{m}$ (B, C, and F); $50 \mu \mathrm{m}$ (D and E).

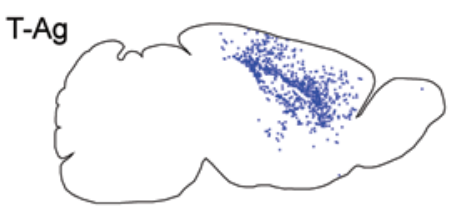

assumed the hypertrophic appearance of infected pre-lytic cells prior to death. Together, these data strongly suggested that the oligodendrocytic death that ensues after JCV infection is primarily apoptotic and occurs in response to T-Ag-triggered forced cell cycle entry, rather than to replicationassociated cytolysis.

Cell cycle arrest at the G2/M transition in astrocytes and GPCs. Polyoma viral replication requires S-phase progression on the part of infected host cells. In particular, previous studies had revealed that JCV genome replication may be facilitated by virally induced cell cycle arrest in G2, prior to the G2/M transition (23). In light of the apparent delay in viral replication in human oligodendroglia, relative to astrocytes and GPCs, we next asked whether infected astrocytes and oligodendrocytes differ in their efficiency of S/G2 traversal.

Since our data indicated that astrocytes and GPCs are the principal vectors of viral spread in vivo, we first investigated the cell cycle status of JCVinfected astroglia by focusing on cyclin $\mathrm{B} 1$, which is normally expressed in the cytoplasm in G2 and enters the nucleus only at the initiation of M-phase. Among cells infected with type $2 \mathrm{~A} \mathrm{JCV}$, $\mathrm{T}-\mathrm{Ag}^{+}$glia expressed nuclear cyclin B1, regardless of their mitotic stage (Figure 7, A-D). In GPCs as well as in astrocytes, cyclin B1 immunoreactivity was localized to the hypertrophic nuclei of infected GPCs (Figure 7, A and E). Furthermore, DAPI staining revealed the frequent presence of $\mathrm{T}-\mathrm{Ag}^{+} \mathrm{JCV}$ infected cells with nuclear cyclin $\mathrm{B}^{+}$ that were not mitotic (Figure 7, C and D), which suggests that JCV infection was associated with cell cycle arrest.

To further define the possibility $6 \mathrm{~F}$ and ref. 22$)$. Whereas $43.5 \% \pm 2.1 \%$ of $\mathrm{TUNEL}^{+} \mathrm{O} 4^{+}$oligodendrocytes expressed T-Ag at $10 \mathrm{DPI}$, only $4.6 \% \pm 0.3 \%$ expressed VP1 $(P<0.001, n=4$ each; Figure $6, \mathrm{G}$ and $\mathrm{H})$. These in vitro data indicate that the vast majority of oligodendrocytes killed by JCV infection die in association with T-Ag expression, never progressing to the point of VP1-defined viral replication. Furthermore, in JCV-infected human glial chimeras, we identified sporadic apoptotic oligodendroglia by TUNEL labeling in vivo and found that a large proportion of these $\mathrm{TUNEL}^{+} \mathrm{O}^{+}$oligodendroglia expressed the mitotic marker Ki67, indicating that their deaths occurred in temporal association with aberrant cell cycle entry. Such apoptotic loss was not observed in infected astrocytes, which instead of phenotype-selective cell cycle arrest by JCV, we investigated the state of p53 phosphorylation in JCV-infected human oligodendrocytes, GPCs, and astrocytes. Because p53 is phosphorylated at Ser15 when DNA damage is detected, phospho-p53(Ser15) expression may be used as a marker of DNA damage, as well as its associated cell cycle arrest at G2/M (23-25). We found that a significantly higher proportion of $\mathrm{T}^{-} \mathrm{Ag}^{+}$astrocytes coexpressed phospho-p53(Ser15) than did uninfected T-Ag cells (Figure 7, E and F). Similarly, among CD140a ${ }^{+}$GPCs infected with type 2A JCV, 36.1\% $\pm 6.1 \%$ expressed phospho-p53(Ser15), while only $3.2 \%$ of uninfected T-Ag- GPCs expressed phospho-p53(Ser15) ${ }^{+}(P<0.001$; Figure 7, G and H). The expression of phospho-p53(Ser15) by T-Ag ${ }^{+}$ 


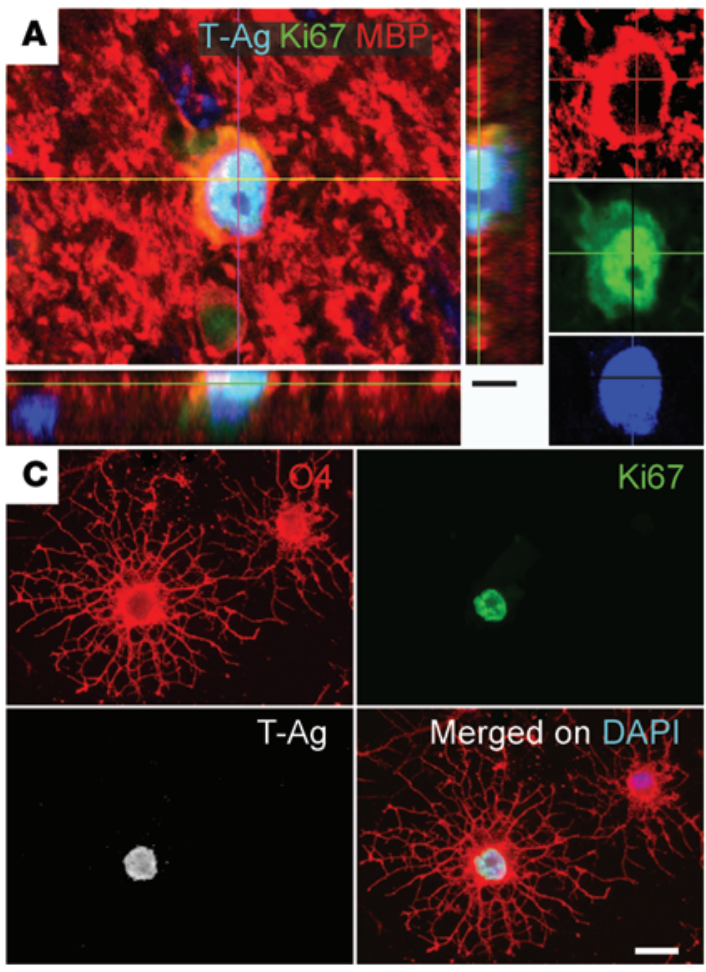

E

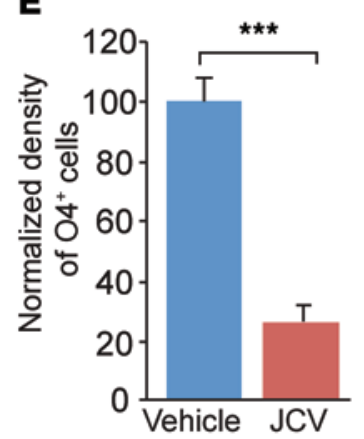

$\mathbf{F}$
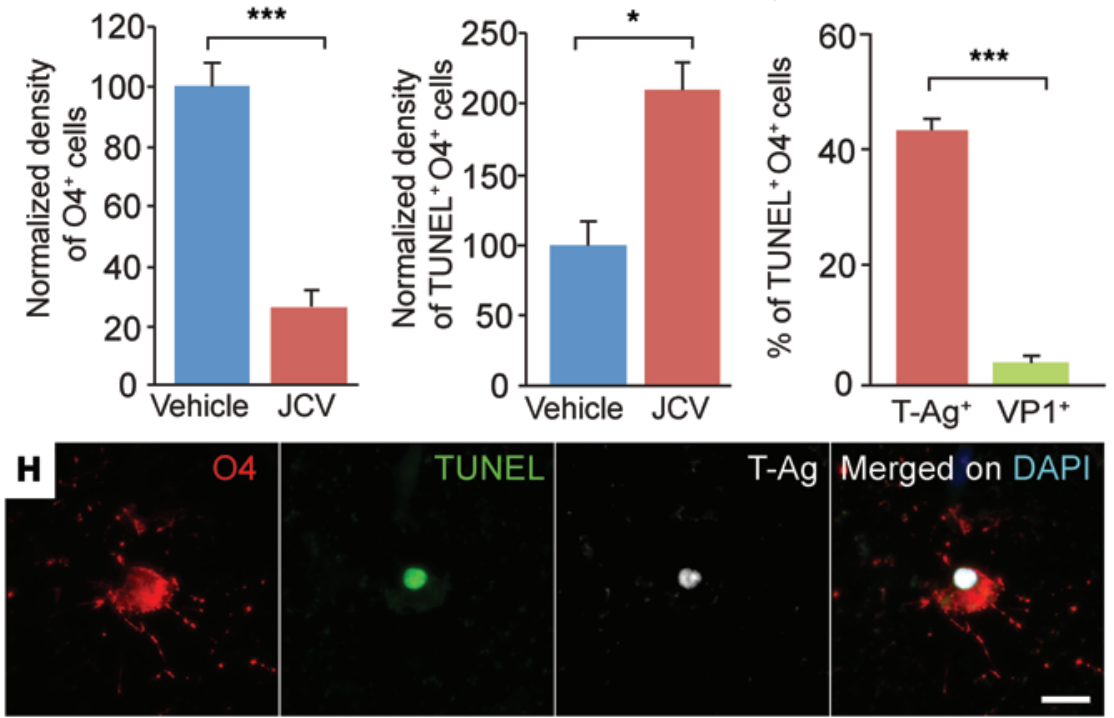

B

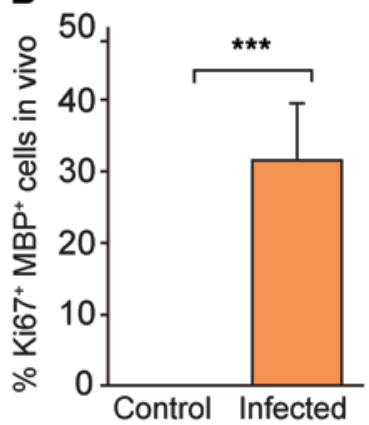

D

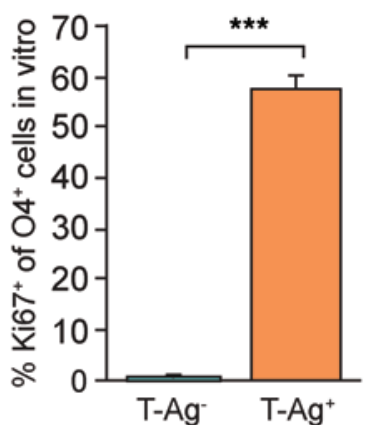

G marked accumulation of cells in G2/M relative to their uninfected controls $(P<0.001$; Supplemental Figure 2A). Interestingly, a fraction of these infected astrocytes appeared hyperploid, suggestive of ongoing DNA replication in infected astroglia, despite their relative cell cycle arrest (Supplemental Figure 2B). Together, these results suggest that JCV infection of human glia triggers phosphorylation of p53 at Ser15 with concomitant cell cycle arrest at G2/M. Whereas in oligodendrocytes this event appeared to trigger apoptotic cell death, in astrocytes and GPCs it was associated with viral replication leading to cell lysis.

JCV VP1 rapidly mutates in vivo. In PML, point mutations in the gene encoding VP1 capsid have been reported at multiple sites of the sialic acid binding region, yet neither cells was even more pronounced in $\mathrm{O}^{+}$oligodendrocytes, among which the majority of $\mathrm{T}-\mathrm{Ag}^{+}$cells expressed phospho-p53(Ser15) (Figure 7, I and J). Indeed, among $\mathrm{T}^{-\mathrm{Ag}^{+}} \mathrm{O}_{4}^{+}$oligodendroglia, $83.6 \% \pm 0.9 \%(n=4)$ were phospho-p53(Ser15)+, compared with $1.3 \% \pm 0.8 \%$ of uninfected $\mathrm{T}-\mathrm{Ag}^{-} \mathrm{O}^{+}$cells in the same plates $(P<0.001,2$-tailed Student's $t$ test). Together, these data strongly suggest that JCV infection was associated with G2/M checkpoint arrest, in all 3 glial phenotypes assessed.

To confirm the possibility of T-Ag-associated mitotic arrest, we next conducted cell cycle analysis of JCV-infected human astroglia, which were derived from GPCs exposed to high serum for 10 days, then exposed to JCV and analyzed 14 days later. We noted that the JCV-infected $\mathrm{T}^{-\mathrm{Ag}^{+}}$astrocytes indeed exhibited the genesis nor the pathogenic role of these mutations has been clear $(26,27)$. Because the propagation and spread of JCV in the

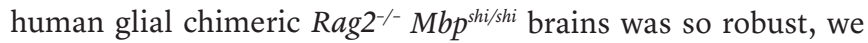
next asked whether JCV mutation might be identified during its replication and spread in this system. To assess viral evolution during active infection in vivo, we sampled 3 sections from each of $5 \mathrm{JCV}$-infected brains from mice that had been killed 3-11 weeks after viral infection; all mice had been neonatally implanted with human GPCs and were given intracallosal injections of Mad-1 JCV between 4 and 16 weeks of age. Of the 5 mice, 4 were Rag2 ${ }^{-/} M{ }^{s} p^{s h i s h i}$ (in which donor human GPCs, astrocytes, and oligodendrocytes coexisted) and 1 was Rag1/- (chimeric only for human donor-derived astrocytes and GPCs). TA PCR 

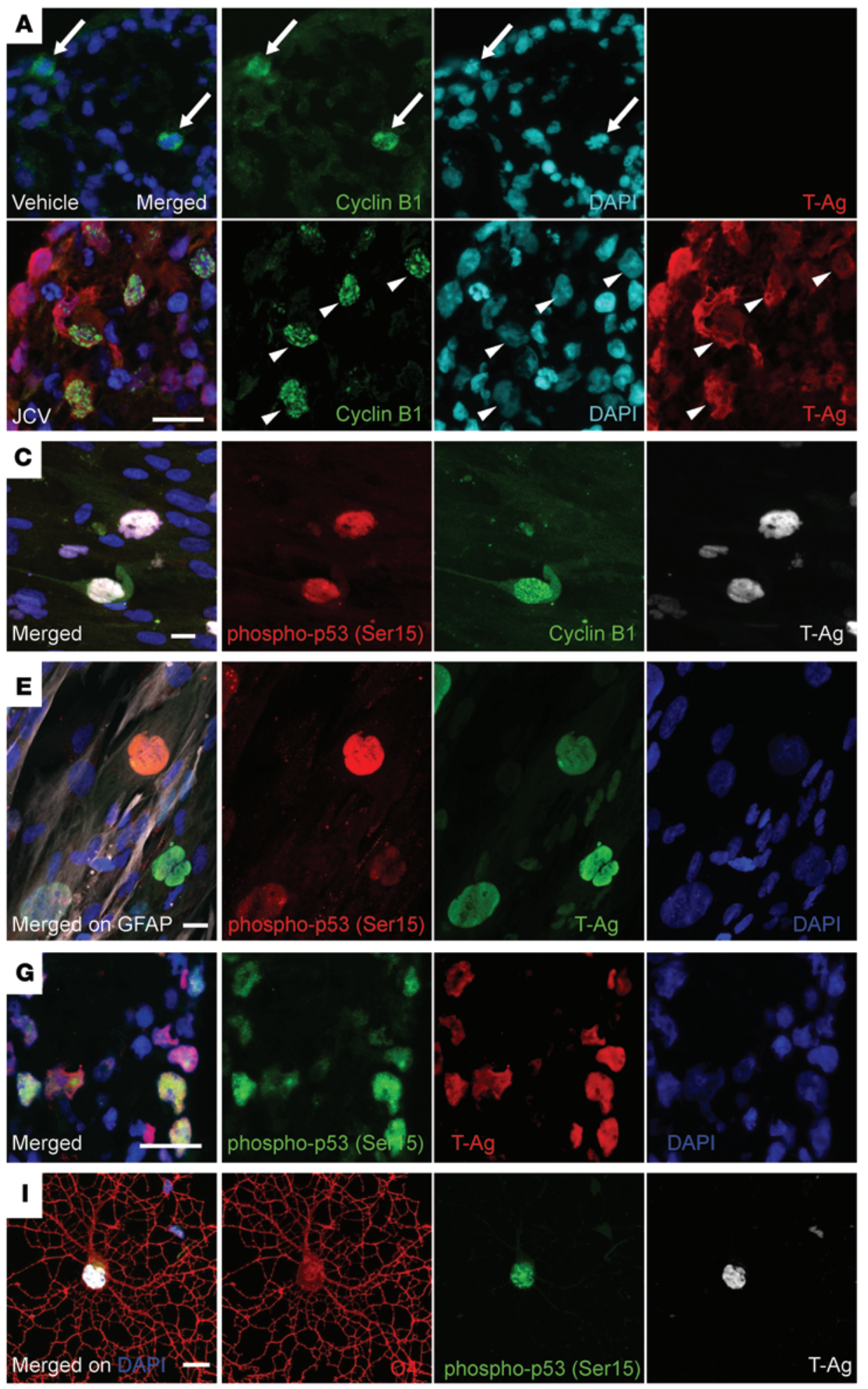

B

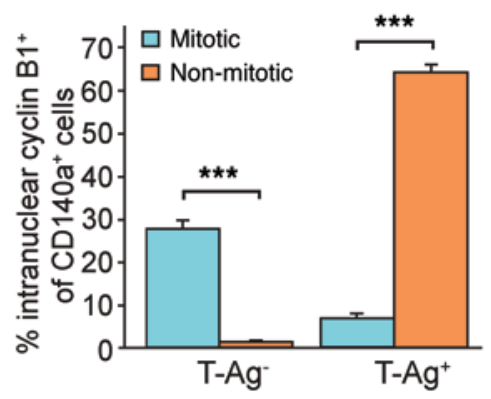

D

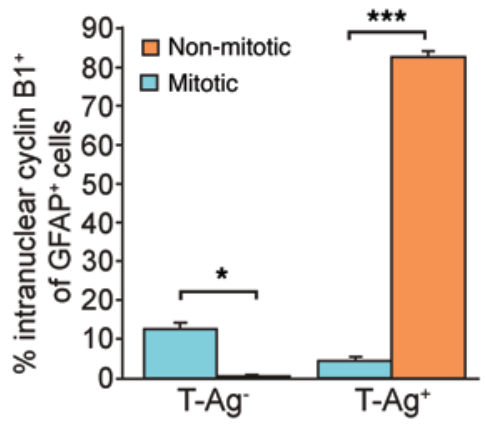

$\mathbf{F}$

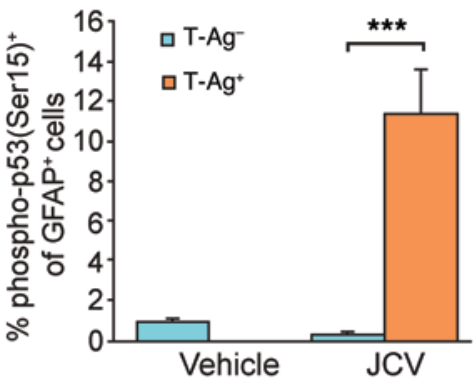

H

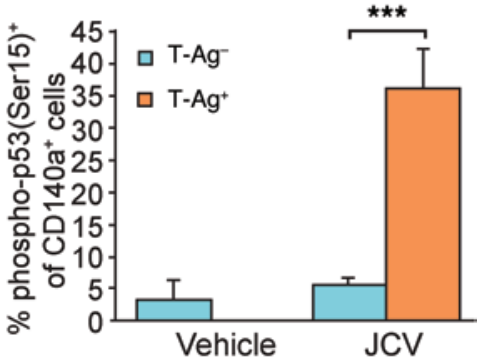

J

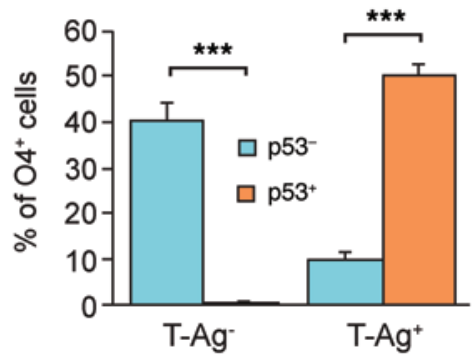

Figure 7. Cell cycle arrest at $\mathbf{G 2} / \mathbf{M}$ in infected glia. $\mathrm{T}-\mathrm{Ag}^{+}$glia expressed the mitosis-associated nuclear protein cyclin B1, as well as the DNA damage and cell cycle arrest-associated phospho-p53(Ser15), regardless of their mitotic stage. (A and B) Vehicle-treated and uninfected (T-Ag) GPCs expressed intranuclear cyclin B1 only when mitotic and in M phase (the latter as assessed by DAPI; arrows), whereas the nuclei of JCV-infected (T-Ag+) GPCs admitted cyclin B1 in a temporally promiscuous fashion (arrowheads). (C) Nuclear phospho-p53(Ser15) and cyclin B1 were coexpressed by mitotically arrested infected astrocytes, but not by uninfected astrocytes. (D) Like control GPCs, uninfected astrocytes (T-Ag-GFAP+) expressed intranuclear cyclin $\mathrm{B} 1$ only in $\mathrm{M}$ phase, whereas JCV-infected astrocytes expressed nuclear cyclin B1 even when not dividing. (E and F) JCV-infected astrocytes (T-Ag ${ }^{+} \mathrm{CFAP}{ }^{+}$) coexpressed phospho-p53(Ser15), associated with G/2M arrest, whereas neither vehicle-treated nor T-Ag astroglia in infected cultures did so to any significant degree. (G and $\mathbf{H}$ ) Similarly, JCV-infected GPCs (T-Ag+CD140a+) coexpressed phospho-p53(Ser15), as well as did infected oligodendrocytes $\left(\mathrm{T}^{\left.-\mathrm{Ag}^{+} \mathrm{O} 4^{+}\right)}\right.$(I and J); for both oligodendrocytes and their progenitors, $\mathrm{T}-\mathrm{Ag}^{+}$cells were significantly more likely to express phospho-p53(Ser15). All cultures were assessed at $10 \mathrm{DPI}$ with type $2 \mathrm{~A}$ JCV (Mad-1 NCCR). Scale bars: $20 \mu \mathrm{m}$. ${ }^{*} P<0.05$; ${ }^{* * *} P<0.001$. 
cloning was used to clone and sequence JCV VP1 DNA from a total of 32 viral clones per sampled section, or 96 per mouse. The VP1 segment of each clone was sequenced and aligned with WT Mad-1 JCV, whose sequence was validated and confirmed in matched aliquots of the injected virus. Among the 480 clones sequenced from the $5 \mathrm{JCV}$-injected mice, 155 (32\%) VP1 genomic mutations were noted compared with the WT Mad-1 sequence; 125 of these yielded mutations in protein sequence. Of these muteins, only 15 distinct loci were represented twice or more in the overall set (Supplemental Table 2); these included 2 mutations - S123C and D66G - which have been described previously in JCV isolated from patients with active PML $(26,27)$. Each of these lies within the sialic acid binding site of VP1, which is particularly notable as VP1 mutants may lose sialic acid dependence for their binding to host cells; this suggests that specific JCV VP1 mutants may acquire selective advantage during host infection (26). This in turn suggests that capsid protein mutations occurring during viral propagation may dynamically shift the infectivity and phenotypic specificity of JCV in vivo over the course of a single host's infection.

VP1 mutants are infective, but show no phenotypic preferences. On the basis of these observations, we next asked whether JCV mutants carrying PML-associated VP1 mutations could infect human glia as well as parental JCV, and if so, whether their relative infectivities differed in either virulence or phenotypic specificity. We therefore assessed the infectivities of 3 VP1 mutations of type 2A JCV (all with PML-associated Mad-1 NCCR; see Methods) both in vitro and in vivo. These VP1 capsid mutants included L55F, K60E, and S269F, each isolated from a different PML patient. We first assessed each mutant in vitro and found that each robustly infected human oligodendrocytes, astrocytes, and GPCs (Supplemental Figure 3).

We next assessed the in vivo infectivities of the 2 most frequent PML-associated mutations, L55F and S269F. Either WT VP1 JCV or mutant VP1 type 2A JCV was injected into the corpus

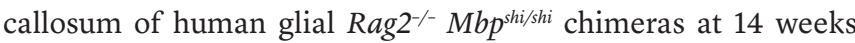
of age, and mice were killed 5 weeks later. Histological analysis revealed that each mutant elicited robust infection in the host, with a recapitulation of both glial infection and local demyelination. At the single time point assessed, no overt differences were noted in the respective infectivities of GPCs, astrocytes, or oligodendrocytes by WT VP1 JCV relative to the 2 VP1-mutant variants (Supplemental Figure 4); all 3 viruses manifested robust infection

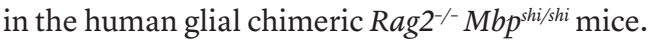

\section{Discussion}

In this study, we used human glial chimeric mice to establish an in vivo model of JCV viral infection and demyelination, mimicking the salient features of PML. We found that in neonatally engrafted

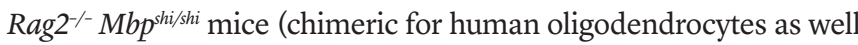
as astrocytes), oligodendrocytic death and demyelination followed astrocytic infection. In vitro, JCV infection of astrocytes was significantly more rapid and efficient than that of oligodendrocytes, whereas in vivo, JCV appeared to propagate primarily via GPCs and astroglia, and much less robustly so in central oligodendrocytes. Indeed, astrocytes proved sufficient for viral propagation in vivo, as shown by rapid and robust viral spread in $\mathrm{Rag1}^{-/-}$mice chimeric only for human GPCs and astrocytes, and utterly lacking human oligodendrocytes.
While human oligodendrocytes exhibited much less frequent viral replication than did astrocytes and progenitors, their infection-associated loss and concomitant demyelination was profound; all macroglial phenotypes were targeted and lost after intracerebral injection of JCV. Yet whereas astrocytic death was associated with cellular lysis in the setting of viral replication and spread, oligodendrocytic death was instead presaged by the aberrant cell cycle entry of these otherwise-postmitotic cells, leading to their arrest in G2 and subsequent apoptotic death. Indeed, this finding provides a mechanistic base for previous observations of apoptotic death by JCV-infected oligodendroglia $(20,28)$. The oligodendrocytic loss and demyelination of JCV-infected human glial chimeras appeared to result from T-Ag-dependent cell cycle induction leading to oligodendrocytic death before viral replication. As a result, when assessed at 5 weeks postinfection, a large proportion of $\mathrm{T}^{-\mathrm{Ag}^{+}}$oligodendrocytes coexpressed Ki67, while oligodendrocytic expression of the replication-associated VP1 protein was uncommon. Our data are therefore suggestive of viral propagation and amplification in an astrocytic reservoir, followed by oligodendrocytic infection, apoptotic death, and demyelination, but with little oligodendroglial viral replication. Although we posit that this concept reflects the typical pattern and pathobiology of JCV's spread in adult humans, it is important to note that the astrocytic and GPC predominance of JCV infection in these brains may also reflect the unique environment of these human glial chimeras; one might readily envision mechanisms by which the relative infectivities of astrocytes and oligodendrocytes might be influenced by cell type-specific adaptations of the human donor cells to the murine brain environment.

Importantly, viral spread within infected brains was associated with rapid and progressive mutation, presumably within the astrocytic reservoir of infection. This process of serial and progressive mutation may provide a selective advantage to the most virulent viral mutants within individual brains, and thus result in the acceleration of viral spread and cytopathogenicity with time. One might then anticipate the emergence and selection of dominant JCV mutants with time during disease progression in any given patient. While JCV mutations have been noted to arise during the course of disease and have been well documented in VP1 $(26,27)$, mutation in JCV's noncoding regulatory regions may be especially critical to disease progression (29-31). Together, these observations suggest that the clonal selection of more infective mutants may occur naturally in human hosts (8); if so, such clonal evolution might account for the terminal acceleration of demyelination often observed in PML patients.

T-Ag can induce aberrant cell cycle entry and S-phase initiation in a variety of somatic phenotypes, through its binding to the tumor suppressor retinoblastoma protein $(\mathrm{Rb})$ and consequent derepression of $\mathrm{Rb}$ targets (16, 32-35). Whereas some mitotic phenotypes may undergo neoplastic transformation by this process (and the polyomaviruses have been causally linked to oncogenesis in various species and cell types; refs. 36-41), in postmitotic phenotypes, as in human oligodendrocytes, $\mathrm{Rb}$ derepression may instead trigger p53-dependent apoptotic cell death (18). Our present data thus suggest that JCV-induced T-Ag may initiate apoptotic oligodendrocytic death via aberrant cell cycle induction, followed by p53-dependent apoptotic cell death before viral replication can be 
completed. While our in vitro and in vivo data collectively suggest that this is the dominant mechanism of JCV-induced oligodendrocytic death, a minority of infected oligodendroglia did progress to viral replication and VP1 expression, which suggests that at least some oligodendroglia may activate mechanisms for apoptotic escape, such as the expression of apoptosis inhibitors (including survivin), which may dominate in astroglia (28). It remains unclear why some JCV-infected oligodendroglia progress to viral replication, whereas most die before reaching that stage, although we posit that this might be a function of the developmental stage at which individual oligodendroglia - or their progenitors - are infected.

In addition to these avenues of death by infected oligodendroglia, our frequent identification of dying oligodendrocytes absent any antigenic evidence of viral infection suggests the concurrent incidence of additional mechanisms for oligodendrocytic loss in JCV-infected brains. Recent studies have highlighted the dependence of oligodendrocytes on local astrocytes $(42)$ and that of neurons upon oligodendroglia $(43,44)$. Given the marked astroglial pathology so evident in JCV-infected brains, the withdrawal of metabolic support of oligodendrocytes by infected astroglia, as well as the latter's potential paracrine cytotoxicity (42), might contribute substantially to both oligodendrocytic loss and its associated neuropathology. Oligodendrocytic loss and demyelination in PML may then represent secondary events, reflecting a combination of paracrine toxicity by infected astroglia, loss of astroglial support of local oligodendrocytes, and apoptotic oligodendrocytic death after direct infection; complicating matters further, each of these mechanisms may be dynamically modulated by concurrent JCV mutation, occurring within a contiguous astrocytic reservoir of virus.

Besides identifying astrocytes and their progenitors as principal substrates for JCV propagation in vivo, with oligodendrocytic death a secondary consequence of viral propagation, this astroglial-centric view of PML pathogenesis may have significant clinical implications for both presentation and treatment of disease. Patients with PML frequently manifest encephalopathic confusion and cognitive deficits long before frank radiographic evidence of demyelination is noted. Our results suggest that the clinical deterioration in these patients may reflect progressive astrocytic dysfunction, especially given the strong influence of astrocytes on synaptic coordination and plasticity $(7,45,46)$. Even a profound degree of astrocytic pathology may not have been previously noted in PML patients, since MRI of the brain is highly biased toward identifying signal abnormalities in the white matter; contemporary MRI has been relatively insensitive to gray matter disruption. Similarly, little focused investigation of astrocytes has been performed in studies of human pathological samples, which have emphasized oligodendrocytic loss and demyelination (21, 47-51), although the early infection of astrocytes in PML has previously been noted $(52,53)$. Together, our present results suggest that astrocytes may be both necessary and sufficient for JCV infection of the brain and that disease-associated astrocytic dysfunction and loss may be at least as important to the neurological deterioration of JCV-infected patients as their progressive demyelination. More broadly, our findings also introduce

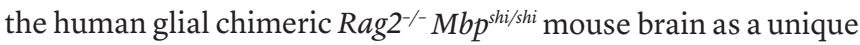
preparation by which the natural history of pathogens specific to the human brain may be assessed in vivo, both longitudinally and in real time, thereby providing fundamentally new opportunities for their mechanistic dissection and therapeutic targeting.

\section{Methods}

Tissue preparation. Human fetal brain tissue was obtained from aborted fetuses (gestational age, 16-22 weeks) under protocols approved by the University of Rochester-Strong Memorial Hospital Research Subjects Review Board. Briefly, cortical tissues were minced and dissociated using papain (Worthington) and DNase (Sigma-Aldrich) as described previously (54), always within 2 hours of extraction. The dissociates were maintained overnight in DMEM/F12/N1-based medium (Life Technologies) supplemented with $10 \mathrm{ng} / \mathrm{ml} \mathrm{FGF2}$ (Sigma-Aldrich) $(5,55)$.

Cell isolation. GPCs were obtained by immunomagnetic sorting (MACS, Miltenyi Biotech) either for the phenotype A2B5 ${ }^{+}$PSA$\mathrm{NCAM}^{-}$, by serial immunodepletion of PSA-NCAM (clone 2-2B, EMD Millipore) and immunoselection of A2B5 (clone A2B5-105, ATCC) (6), or for the more specific $\mathrm{CD} 140 \mathrm{a}^{+}$phenotype, using anti-human CD140a (clone $\alpha$ R1; BD Biosciences) followed by anti-mouse $\operatorname{IgG}_{2 a+b}$ microbeads (Miltenyi Biotech) (14). A2B5+PSA-NCAM cells were used for all in vivo experiments, whereas in vitro experiments were done primarily with $\mathrm{CD} 140 \mathrm{a}^{+}$cells; the latter comprise the fraction of $\mathrm{A}^{2} \mathrm{~B}^{+} / \mathrm{PSA}^{-} \mathrm{NCAM}^{-}$cells that includes all potentially oligoneogenic GPCs, while largely excluding committed astroglia. After MACS isolation, the cells were maintained in DMEM/F12/N1 supplemented with $20 \mathrm{ng} / \mathrm{ml}$ PDGF-AA (PeproTech Inc.) and $10 \mathrm{ng} / \mathrm{ml} \mathrm{FGF-2,} \mathrm{then} \mathrm{trans-}$ planted into the brains of neonatal mice within 3 days of sorting.

For preparing specific phenotypes, GPCs were obtained by CD140a sorting, while oligodendroglia were then derived from these GPCs by culture for 1 week in media supplemented with T3 (SigmaAldrich) and IGF-1 (Sigma-Aldrich) $(14,56)$. Astrocytes were isolated from the tissue dissociates using MACS targeting the astroglial hyaluronate receptor CD44 (57), using conjugated microbeads (Miltenyi Biotech; clone DB105) according to the manufacturer's instructions.

Viral construction. Type 1A rearranged NCCR JCV genome (Mad1; GenBank accession no. NC_001699) in the Bluescript plasmid vector was a gift of R. Frisque (Pennsylvania State University, University Park, Pennsylvania, USA). Type 2A VP1 archetype NCCR JCV genome (type 2A; GenBank accession no. AY121915) was synthesized in 3 fragments (GeneArt) and subsequently ligated to yield the full-length type $2 \mathrm{~A} \mathrm{JCV}$ genome, cloned in an E. coli replicon. To create the type $2 \mathrm{~A}$ rearranged viral genome, type $2 \mathrm{~A}$ JCV NCCR was replaced with rearranged NCCR of Mad-1, by exchanging a 416-bp Nco1 fragment from the archetype genome with 425-bp Nco1 fragments of pBS-Mad-1. Site-directed mutagenesis (QuikChange; Agilent Technologies) was performed on this rearranged type $2 \mathrm{~A}$ vector in order to incorporate the VP1 mutations L55F (type 2A 55F VP1 virus), K60E (type 2A 60E VP1 virus), or S269F (type 2A 269F VP1 virus).

Viral production and purification. To produce virus, viral genomes were excised from their corresponding replication plasmids with EcoR1 restriction endonuclease digestion. The linearized viral genomes were recircularized in a dilute ligation reaction $(5 \mu \mathrm{g} / \mathrm{ml})$ at room temperature overnight, ethanol precipitated and resuspended in TE, and transfected into 293FT cells (Invitrogen) with FuGeneHD (Roche). After 1 week, cells were split into 20 T160 flasks; 2 weeks later, the cultures were collected for virus purification. During these last 2 weeks of virus production, culture medium was added to cultures rather than replaced. Supernatant 
was cleared at 2,500 $g$ for 20 minutes, and the pellet then resuspended in 1:20 original volume and used for virus purification. The resuspended pellet was freeze-thawed 3 times to disrupt cells, followed by treatment with benzonase ( $250 \mathrm{U} / \mathrm{ml}$; Sigma-Aldrich) and neuraminidase (20 U/ $\mathrm{ml}$; NEB) at $37^{\circ} \mathrm{C}$ for 3 hours, to aid in dissociation of viral particles from cellular debris. At that point, detergents including 0.1\% deoxycholate and $0.5 \%$ TritonX-100 were added, and incubation continued for another hour. The resultant suspension was spun at 2,500 $\mathrm{g}$ for 30 minutes at $4^{\circ} \mathrm{C}$, the pellet discarded, and the supernatant loaded onto $30 \%$ sucrose in low-salt buffer (10 mM HEPES pH 7.9; $1 \mathrm{mM} \mathrm{CaCl}_{2} ; 1 \mathrm{mM} \mathrm{MgCl}_{2} ; 5 \mathrm{mM}$ $\mathrm{KCl}$ ), then centrifuged using a SW28 rotor at $140,000 \mathrm{~g}$ for 3 hours at $4^{\circ} \mathrm{C}$. The resultant pellet was soaked in high-salt buffer (10 mM HEPES pH 7.9; $1 \mathrm{mM} \mathrm{CaCl} ; 1 \mathrm{mM} \mathrm{MgCl} ; 5 \mathrm{mM} \mathrm{KCl} ; 0.8 \mathrm{M} \mathrm{NaCl}$ ) overnight, then resuspended and respun through $30 \%$ sucrose. The final pellet was again soaked overnight in high-salt buffer, resuspended, and then aliquoted and frozen at $-80^{\circ} \mathrm{C}$. Final JCV preparations for both Mad- 1 and its derived VP1-mutant forms were in the range of $1.6 \times 10^{12}-2.2 \times 10^{13} \mathrm{GE} / \mathrm{ml}$.

Viral sequencing. JCV VP1 was sequenced from a sample of infected cells identified in each infected brain, using the forebrain hemisphere contralateral to that used for histological analysis. Each sampled hemisphere was cut into $12-\mathrm{mm} \times 1-\mathrm{mm}$ coronal sections. DNA was then isolated from each slice using RecoverAll Total Nucleic Acid Isolation Kit for FFPE Tissues (Life Technologies), and the isolated DNA was used for qPCR with JCV-specific primer probe sets. 100 ng total DNA from the second, fourth, and ninth sections was amplified using the Herculase II Fusion Enzyme system (catalog no. 600677, Agilent Technologies). The VP1 coding region was amplified using full-length VP1 specific primers 5'-CCTCAATGGATGTTGCCTTT-3' and 5'-AAAACCAAAGACCCCTC-3'. PCR amplification products were then cloned using the TOPO TA Cloning Kit (Invitrogen), transformed, and plated according to the manufacturer's specifications. 32 individual colonies for each cloned product ( 96 colonies per brain) were then screened and sequenced, using an Applied Biosystems 3730XL DNA Analyzer with BigDye Terminator version 3.1 chemistry. As a control, $100 \mathrm{ng}$ viral DNA (Mad-1) prepared from the same virus injected into that mouse brain was amplified and cloned using the same conditions as the DNA prepared from brain tissue (in this, H122Y and H122P mutations were noted relative to Mad-1). 96 individual colonies were sequenced, to allow us to estimate the mutation rate of the starting viral genotype. Coding mutations were identified after translating the DNA sequence and aligning the predicted protein sequence to that of Mad-1.

Infection in vitro. $\mathrm{CD} 140 \mathrm{a}^{+} \mathrm{GPCs}$ and $\mathrm{CD} 44^{+}$astrocytes were plated at 5,000 cells $/ \mathrm{cm}^{2}$ on Permanox chamber slides (Thermo Scientific) coated with poly-L-ornithine (Sigma-Aldrich) plus laminin (BD) or $12-\mathrm{mm}$ coverslips coated with Matrigel ( $33 \mu \mathrm{g} / \mathrm{ml}$; BD Biosciences). Oligodendrocyte progenitor cells were allowed to differentiate into oligodendrocytes for 7 days in Neurobasal medium (Life Technologies) supplemented with $1 \times$ B27 (Life Technologies) and $30 \mathrm{ng} / \mathrm{ml} \mathrm{T3,10} \mathrm{ng/}$ $\mathrm{ml} \mathrm{IGF-1,} \mathrm{and} 10 \mathrm{ng} / \mathrm{ml} \mathrm{NT}-3$ (PeproTech). The cells were infected with $\mathrm{JCV}$ in $250 \mu \mathrm{l}$ medium at $10^{5} \mathrm{GE} /$ cell for 2 hours at $37^{\circ} \mathrm{C}$. CD $44^{+} \mathrm{MACS}-$ derived astrocytes were maintained in the DMEM/F12/N1-based medium with $1 \%$ platelet-depleted FBS (Cocalico Biologicals Inc.) and infected 2 days after plating at $10^{5} \mathrm{GE} /$ cell. CD140a ${ }^{+}$MACS-derived GPCs were plated in ultra-low-attachment 24-well plates (Corning Inc.) at $10^{5}$ cells/well in Neurobasal medium supplemented with $1 \times$ B27, $20 \mathrm{ng} / \mathrm{ml}$ PDGF-AA, and $10 \mathrm{ng} / \mathrm{ml} \mathrm{FGF-2.} \mathrm{The} \mathrm{following} \mathrm{day,} \mathrm{the}$ cells were infected with JCV at $10^{5} \mathrm{GE} /$ cell for 2 hours.
Animals and GPC transplantation. In this study, 2 immunodeficient mouse strains were used: one myelin deficient and the other normally myelinated. Homozygous myelin-deficient shiverer mice $\left(M b p^{s h i / s h}\right)$ were crossed with homozygous Rag2-- immunodeficient mice (Taconic) to generate a line of myelin-deficient and immunodeficient Rag2 $^{-/-} \mathrm{Mbp} \mathrm{p}^{\mathrm{sh} / \mathrm{shi}}$ mice. In addition, normally myelinated and immunodeficient Rag1 ${ }^{-1-}$ mice were obtained from the Jackson Laboratory. All mice were bred and housed in a pathogen-free environment in accordance with the University of Rochester animal welfare regulations. Newborn pups were transplanted within a day of birth, with 200,000-400,000 donor cells delivered across 4 injection sites (6). In all determinations of animal use, group assignment, numbers, experimental design, and description of results in this study, we attempted to follow the ARRIVE reporting guidelines (58).

Virus administration. Adult mice were anesthetized with a mixture of ketamine (JHP Pharmaceuticals) and xylazine (Akorn Inc.), in accordance with University of Rochester protocols. JCV, prepared as indicated to a final concentration of $1.6 \times 10^{12}-2.2 \times 10^{13} \mathrm{GE} / \mathrm{ml}$, was thawed and resuspended in HBSS buffer (Life Technologies) before injection. $1 \mu \mathrm{l}$ virus was injected bilaterally into the corpus callosum (total, $2 \mu \mathrm{l}$; $\mathrm{AP},+0.5 ; \mathrm{ML}, \pm 0.8 ; \mathrm{DV},-1.4$ ), using a Gastight (Hamilton) syringe.

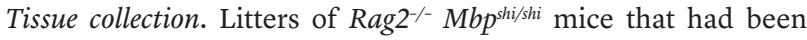
transplanted neonatally with human cells were injected with Mad-1

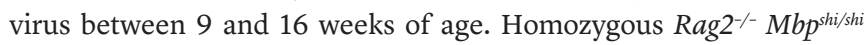
mice in our colony did not reliably live longer than 20-22 weeks. Accordingly, when infected mice were noted to be moribund, they were euthanized with sodium pentobarbital (Nembutal) and transcardially perfused with HBSS followed by $4 \%$ paraformaldehyde/ phosphate buffer (PFA/PB). The brains were then extracted from the skull, postfixed for 2 hours in the same fixative, and cryoprotected in a sucrose buffer. Serial sagittal sections were cut at $14 \mu \mathrm{m}$ on a cryostat (Leica) and mounted on glass slides. Myelin WT Rag1-/- mice were injected with JCV at 16 weeks and sacrificed at 28 weeks of age.

Immunocytochemistry in culture. Adherent cells were fixed with $4 \%$ PFA/PB and immunolabeled using primary antibodies as follows: mouse anti-T-Ag antibody (1:300 dilution; Pab2003, gift of R. Frisque); mouse anti-large T-Ag antibody (1:50 dilution; Pab416, Calbiochem): rabbit anti-SV40 T-Ag antibody (1:50 dilution; v-300, SantaCruz; known to cross-react with JCV T-Ag); mouse anti-VP1 antibody (1:3,000 dilution; PAB597, Biogen); chicken anti-GFAP antibody (1:800 dilution; Chemicon); rabbit anti-CD140a antibody (1:800 dilution; D13C6, Cell Signaling Technology); mouse antiphospho-p53(Ser15) antibody (1:100 dilution; Cell Signaling Technology); rabbit anti-cyclin B1 antibody (1:180 dilution; Cell Signaling Technology); rabbit anti-Ki67 antibody (1:300 dilution; Thermo). Oligodendrocytes were stained as live cells with supernatant from O4 hybridoma (gift of I. Duncan, University of Wisconsin, Madison, Wisconsin, USA) at $10 \mu \mathrm{g} / \mathrm{ml}$, followed by fixation with $4 \% \mathrm{PFA} / 0.1$ $\mathrm{M}$ PB. CD140a ${ }^{+}$GPCs were collected as spheres, fixed with $2 \% \mathrm{PFA} /$ $\mathrm{PB}$ for 10 minutes, immersed in $15 \%$ followed by $30 \%$ sucrose/PB, cut at $6 \mu \mathrm{m}$ on a cryostat, mounted on glass slides, and subjected to immunocytochemistry. Alexa Fluor 488-, 594-, and 647-conjugated goat secondary antibodies against appropriate animal species and Ig classes (Invitrogen) were used at 1:1,000 dilution. The nucleus was counterstained with DAPI at $600 \mathrm{nM}$.

Immunohistochemistry in sections. Slide-mounted sections were rehydrated with $0.1 \mathrm{M}$ PBS and permeabilized and blocked for 1 hour with PBS containing 0.1\% Triton X-100 and 10\% normal goat serum. 
Immunolabeling was performed using the following primary antibodies: mouse anti-human nuclear antigen, clone 235-1 (1:800 dilution; MAB1281, Millipore); mouse anti-VP1 (1:1,000 dilution; PAB597, Biogen); rabbit anti-SV40 VP1 (1:500 dilution; AB53977, Abcam); mouse anti-T-Ag (1:60 dilution; PAB2003, gift of R. Frisque); rabbit antiSV40 T-Ag, v-300 (1:50 dilution; SC-20800, Santa Cruz); rat antiMBP (1:25 dilution; ab7349-1, Abcam); mouse anti-human GFAP SMI211 (1:500 dilution; ADG 050809, Covance); rabbit anti-GFAP (1:800 dilution; ab33922-100, Abcam); mouse anti-human NG2 (1:200 dilution; MAb 2029, Millipore); rabbit anti-NG2 (1:200 dilution; AB5320, Millipore); rabbit anti-Ki67 (1:50 dilution; clone SP6, LabVision); and rabbit anti-CD140a (1:400 dilution; MAb 3174, Cell Signaling Technologies). Alexa Fluor-conjugated secondary antibodies were used at 1:400 dilution (Invitrogen). Slides were coverslipped using Vectashield mounting media with DAPI (Vector Labs).

Image analysis. The incidence of individual human phenotypes was estimated using the Optical Fractionator Program of Stereo Investigator (MBF Bioscience). Stained sagittal sections were imaged as $7-\mu \mathrm{m}$ stacks of 7 superimposed optical slices, taken at $0.2-\mu \mathrm{m}$ intervals in the corpus callosum at $\times 20$, using an Olympus BX51 with Ludl stage. The entire corpus callosum (excluding fimbria) was mapped for each of 2 random sections, either $336-672 \mu \mathrm{m}$ or $672-1,008 \mu \mathrm{m}$ from the midline, for each experimental mouse.

In situ detection of JCV genome. JCV infection was also detected by DNA in situ hybridization. The slides were incubated with a biotinylated DNA probe for the JCV genome (Enzo Life Sciences) at $2 \mu \mathrm{g} / \mathrm{ml}$ at $95^{\circ} \mathrm{C}$ for 2 minutes, then at room temperature for 1 hour. The hybridization signal was detected by incubating with fluorescein-labeled avidin (1:400 dilution; Invitrogen).

Flow cytometric cell cycle analysis. Cell cycle analysis was performed by flow cytometric evaluation of propidium iodide-exposed cells after immunolabeling for T-Ag. Fetal astrocytes were infected with type 2A VP1 JCV (Mad-1 NCCR) at $10^{4} \mathrm{GE} /$ cell in 6-well plates, passaged twice in 60-mm dishes, then plated into 100-mm dishes. 14 days after inoculation, cells were harvested using Accutase and fixed with $70 \%$ ethanol overnight at $-20^{\circ} \mathrm{C}$. The cells were immunolabeled with rabbit anti-T-Ag polyclonal antibody (1:500 dilution; v-300, SantaCruz) followed by Alexa Fluor 488-conjugated secondary antibody (1:1,000 dilution). DNA content was detected with propidium iodide $(4 \mu \mathrm{g} / \mathrm{ml})$. Flow cytometry was performed using FACS Canto (BD Biosciences), and data were analyzed with FlowJo software (Tree Star). The percentage of cells in each cell cycle was calculated based on the Dean-Jett-Fox model in FlowJo, comparing vehicle-treated and JCV-infected astrocytes.

Statistics. Data are provided as mean \pm SEM. Both 1- and 2-way ANOVA were performed with Bonferroni corrections for multiple comparisons. All statistical analyses were performed using Prism (GraphPad Software), and a $P$ value less than 0.05 was considered statistically significant.

Study approval. Human fetal brain tissue was obtained under protocols approved by the University of Rochester-Strong Memorial Hospital Research Subjects Review Board. Deidentified human fetal brain tissue was obtained within 1 hour of surgical acquisition from the University of Rochester Department of Pathology; no patient identifiers were available to study personnel. All animal protocols were in accordance with University of Rochester animal welfare regulations.

\section{Acknowledgments}

This work was supported by Biogen Idec, NINDS grant R01NS75345, the New York State Stem Cell Research Program (NYSTEM), and the National Multiple Sclerosis Society. We thank Richard Frisque and Ian Duncan for gifts of antibodies; Margot Brickelmaier, Jeff Thompson, Ken Simon, Wanyong Zeng, Eric Baetscher, Kathryn Doyle, Christopher Tonkin, Michele McAuliffe, and John Anderson of Biogen for technical support; Adam Cornwell for statistical advice and support; and Abdellatif Benraiss for imaging assistance.

Address correspondence to: Steven A. Goldman, Center for Translational Neuromedicine, University of Rochester Medical Center, Rochester, New York 14642, USA. Phone: 585.275.9550; E-mail: steven_goldman@urmc.rochester.edu.
1. Berger JR. Progressive multifocal leukoencephalopathy. Current Neurol Neurosci Reports. 2007;7(6):461-469.

2. Major EO. Progressive multifocal leukoencephalopathy in patients on immunomodulatory therapies. Annu Rev Med. 2010;61:35-47.

3. Tan CS, et al. Detection of JC virus-specific immune responses in a novel humanized mouse model. PloS One. 2013;8(5):e64313.

4. Matoba T, et al. An siRNA against JC virus (JCV) agnoprotein inhibits JCV infection in JCV-producing cells inoculated in nude mice. Neuropathology. 2008;28(3):286-294.

5 . Windrem MS, et al. Fetal and adult human oligodendrocyte progenitor cell isolates myelinate the congenitally dysmyelinated brain. Nat Med. 2004;10(1):93-97.

6. Windrem MS, et al. Neonatal chimerization with human glial progenitor cells can both remyelinate and rescue the otherwise lethally hypomyelinated shiverer mouse. Cell Stem Cell. 2008;2(6):553-565.

7. Han X, et al. Forebrain engraftment by human glial progenitor cells enhances synaptic plasticity and learning in adult mice. Cell Stem Cell. 2013;12(3):342-353.

8. Sunyaev SR, Lugovskoy A, Simon K, Gorelik L. Adaptive mutations in the JC virus protein capsid are associated with progressive multifocal leukoencephalopathy (PML). PLoS Genet. 2009;5(2):e1000368.

9. Major EO, Vacante DA. Human fetal astrocytes in culture support the growth of the neurotropic human polyomavirus, JCV. J Neuropathol Exp Neurol. 1989;48(4):425-436.

10. Monaco MCG, Maric D, Bandeian A, Leibovitch E, Yang W, Major EO. Progenitor-derived oligodendrocyte culture system from human fetal brain. J Vis Exp. 2012;(70):4274.

11. Seth P, Diaz F, Tao-Cheng JH, Major EO. JC virus induces nonapoptotic cell death of human central nervous system progenitor cell-derived astrocytes. J Virol. 2004;78 (9):4884-4891.

12. Radhakrishnan S, Otte J, Enam S, Del Valle L, Khalili K, Gordon J. JC virus-induced changes in cellular gene expression in primary human astrocytes. J Virol. 2003;77 (19):10638-10644.

13. Messam CA, Hou J, Gronostajski RM, Major EO.

Lineage pathway of human brain progenitor cells identified by JC virus susceptibility. Ann Neurol. 2003;53(5):636-646.

14. Sim FJ, McClain CR, Schanz SJ, Protack TL, Windrem MS, Goldman SA. CD140a identifies a population of highly myelinogenic, migrationcompetent and efficiently engrafting human oligodendrocyte progenitor cells. Nat Biotechnol. 2011;29(10):934-941.

15. Aksamit AJ Jr. Progressive multifocal leukoencephalopathy: a review of the pathology and pathogenesis. Microscopy Res Tech. 1995;32(4):302-311.

16. Dickmanns A, et al. The kinetics of simian virus 40-induced progression of quiescent cells into S phase depend on four independent functions of large T antigen. J Virol. 1994;68(9):5496-5508.

17. Busser J, Geldmacher DS, Herrup K. Ectopic cell cycle proteins predict the sites of neuronal cell death in Alzheimer's disease brain. J Neurosci. 1998;18(8):2801-2807. 
18. Herrup K, Neve R, Ackerman SL, Copani A. Divide and die: cell cycle events as triggers of nerve cell death. J Neurosci. 2004;24(42):9232-9239.

19. Yang Y, Mufson EJ, Herrup K. Neuronal cell death is preceded by cell cycle events at all stages of Alzheimer's disease. J Neurosci. 2003;23(7):2557-2563.

20. Merabova N, et al. JC virus agnoprotein inhibits in vitro differentiation of oligodendrocytes and promotes apoptosis. J Virol. 2008;82(3):1558-1569.

21. Richardson-Burns SM, Kleinschmidt-DeMasters BK, DeBiasi RL, Tyler KL. Progressive multifocal leukoencephalopathy and apoptosis of infected oligodendrocytes in the central nervous system of patients with and without AIDS. Arch Neurol. 2002;59(12):1930-1936.

22. Negoescu A, et al. In situ apoptotic cell labeling by the TUNEL method: improvement and evaluation on cell preparations. J Histochem Cytochem. 1996;44(9):959-968.

23. Orba $\mathrm{Y}$, et al. Large $\mathrm{T}$ antigen promotes JC virus replication in G2-arrested cells by inducing ATMand ATR-mediated G2 checkpoint signaling. J Biol Chem. 2010;285(2):1544-1554.

24. Banin S, et al. Enhanced phosphorylation of p53 by ATM in response to DNA damage. Science. 1998;281(5383):1674-1677.

25. Shieh SY, Ikeda M, Taya Y, Prives C. DNA damage-induced phosphorylation of p53 alleviates inhibition by MDM2. Cell. 1997;91(3):325-334.

26. Gorelik L, et al. Progressive multifocal leukoencephalopathy (PML) development is associated with mutations in JC virus capsid protein VP1 that change its receptor specificity. J Infect Dis. 2011;204(1):103-114.

27. Reid CE, et al. Sequencing and analysis of JC virus DNA from natalizumab-treated PML patients. J Infect Dis. 2011;204(2):237-244.

28. Pina-Oviedo S, et al. Effects of JC virus infection on anti-apoptotic protein survivin in progressive multifocal leukoencephalopathy. Am J Pathol. 2007;170(4):1291-1304.

29. Frisque RJ. Regulatory sequences and viruscell interactions of JC virus. Prog Clin Biol Res. 1983;105:41-59.

30. Kim HS, Goncalves NM, Henson JW. Glial cellspecific regulation of the JC virus early promoter by large T antigen. J Virol. 2000;74(2):755-763.

31. Pfister LA, Letvin NL, Koralnik IJ. JC virus regulatory region tandem repeats in plasma and central nervous system isolates correlate with poor clinical outcome in patients with progressive multifocal leukoencephalopathy. J Virol. 2001;75(12):5672-5676.

32. Caracciolo V, Reiss K, Khalili K, De Falco G, Gior- dano A. Role of the interaction between large $\mathrm{T}$ antigen and $\mathrm{Rb}$ family members in the oncogenicity of JC virus. Oncogene. 2006;25(38):5294-5301.

33. DeCaprio JA, et al. SV4O large tumor antigen forms a specific complex with the product of the retinoblastoma susceptibility gene. Cell. 1988;54(2):275-283.

34. Saenz-Robles MT, et al. Intestinal hyperplasia induced by simian virus 40 large tumor antigen requires E2F2. J Virol. 2007;81(23):13191-13199.

35. Xiao A, Wu H, Pandolfi PP, Louis DN, Van Dyke $\mathrm{T}$. Astrocyte inactivation of the $\mathrm{pRb}$ pathway predisposes mice to malignant astrocytoma development that is accelerated by PTEN mutation. Cancer Cell. 2002;1(2):157-168.

36. Hermeking $\mathrm{H}$, et al. Role of $\mathrm{c}-\mathrm{myc}$ in simian virus 40 large tumor antigen-induced DNA synthesis in quiescent 3T3-L1 mouse fibroblasts. Proc Natl Acad Sci U S A. 1994;91(22):10412-10416.

37. Krynska B, et al. Role of cell cycle regulators in tumor formation in transgenic mice expressing the human neurotropic virus, JCV, early protein. JCell Biochem. 1997;67(2):223-230.

38. London WT, et al. Brain tumors in owl monkeys inoculated with a human polyomavirus (JC virus). Science. 1978;201(4362):1246-1249.

39. Manfredi JJ, Prives C. The transforming activity of simian virus 40 large tumor antigen. Biochim Biophysica Acta. 1994;1198(1):65-83.

40. Tevethia MJ, Bonneau RH, Griffith JW, Mylin L. A simian virus 40 large $\mathrm{T}$-antigen segment containing amino acids 1 to 127 and expressed under the control of the rat elastase- 1 promoter produces pancreatic acinar carcinomas in transgenic mice. J Virol. 1997;71(11):8157-8166.

41. Walker DL, Padgett BL, ZuRhein GM, Albert AE, Marsh RF. Human papovavirus (JC): induction of brain tumors in hamsters. Science. 1973;181(4100):674-676.

42. Bruck W, et al. Reduced astrocytic NF-kappaB activation by laquinimod protects from cuprizone-induced demyelination. Acta Neuropathol. 2012;124(3):411-424.

43. Funfschilling U, et al. Glycolytic oligodendrocytes maintain myelin and long-term axonal integrity. Nature. 2012;485(7399):517-521.

44. Benediktsson AM, et al. Neuronal activity regulates glutamate transporter dynamics in developing astrocytes. Glia. 2012;60(2):175-188.

45. Kang J, Jiang L, Goldman SA, Nedergaard M. Astrocyte-mediated potentiation of inhibitory synaptic transmission. Nat Neurosci. 1998;1(8):683-692.

46. Araque A, Parpura V, Sanzgiri RP, Haydon PG. Tripartite synapses: glia, the unacknowledged partner. Trends Neurosci. 1999;22(5):208-215.

47. Gerber MA, Shah KV, Thung SN, Zu Rhein GM. Immunohistochemical demonstration of common antigen of polyomaviruses in routine histologic tissue sections of animals and man. Am J Clin Pathol. 1980;73(6):795-797.

48. Greenlee JE, Keeney PM. Immunoenzymatic labelling of JC papovavirus $\mathrm{T}$ antigen in brains of patients with progressive multifocal leukoencephalopathy. Acta Neuropathol. 1986;71(1-2):150-153.

49. Jochum W, Weber T, Frye S, Hunsmann G, Luke W, Aguzzi A. Detection of JC virus by anti-VP1 immunohistochemistry in brains with progressive multifocal leukoencephalopathy. Acta Neuropathol. 1997;94(3):226-231.

50. Mazlo M, Tariska I. Morphological demonstration of the first phase of polyomavirus replication in oligodendroglia cells of human brain in progressive multifocal leukoencephalopathy (PML). Acta Neuropathol. 1980;49(2):133-143.

51. Zurhein G, Chou SM. Particles resembling papova viruses in human cerebral demyelinating disease. Science. 1965;148(3676):1477-1479.

52. Ironside JW, Lewis FA, Blythe D, Wakefield EA. The identification of cells containing JC papovavirus DNA in progressive multifocal leukoencephalopathy by combined in situ hybridization and immunocytochemistry.J Pathol. 1989;157(4):291-297.

53. Astrom KE, Stoner GL. Early pathological changes in progressive multifocal leukoencephalopathy: a report of two asymptomatic cases occurring prior to the AIDS epidemic. Acta Neuropathol. 1994;88(1):93-105.

54. Roy N, Windrem M, Goldman SA. Progenitor cells of the adult white matter. In: Lazzarini $\mathrm{R}$, ed. Myelin Biology and Disorders. Amsterdam, the Netherlands: Elsevier; 2004:259-287.

55. Keyoung HM, et al. High-yield selection and extraction of two promoter-defined phenotypes of neural stem cells from the fetal human brain. Nat Biotechnol. 2001;19(9):843-850.

56. Holmseth S, Zhou Y, Follin-Arbelet VV, Lehre KP, Bergles DE, Danbolt NC. Specificity controls for immunocytochemistry: the antigen preadsorption test can lead to inaccurate assessment of antibody specificity. J Histochem Cytochem. 2012;60(3):174-187.

57. Liu Y, et al. CD44 expression identifies astrocyte-restricted precursor cells. Dev Biol. 2004;276(1):31-46.

58. Kilkenny C, Browne WJ, Cuthill IC, Emerson M, Altman DG. Improving bioscience research reporting: the ARRIVE guidelines for reporting animal research. PLoS Biol. 2010;8(6):e1000412. 